\title{
1 Global distribution of anaerobic dichloromethane degradation potential
}

2

3 Short Title: Anaerobic dichloromethane biodegradation

4 Robert L. Hettich ${ }^{6}$, and Frank E. Löffler $1,2,3,4,6 *$ Tennessee, Knoxville, TN 37996, USA

Phone: (865) $9744933 \quad$ Email: frank.loeffler@utk.edu Abstract

Robert W. Murdoch ${ }^{1} \uparrow$, Gao Chen ${ }^{1,2}$, Fadime Kara Murdoch ${ }^{1,7} \uparrow$, E. Erin Mack ${ }^{5}$, Manuel I. Villalobos Solis ${ }^{6}$,

${ }^{1}$ Center for Environmental Biotechnology, ${ }^{2}$ Department of Civil and Environmental Engineering, ${ }^{3}$ Department of Microbiology, ${ }^{4}$ Department of Biosystmes Engineering and Soil Science, University of

${ }^{5}$ Corteva Environmental Remediation, Corteva Agriscience, Wilmington, DE 19805, USA

${ }^{6}$ Biosciences Division, Oak Ridge National Laboratory, Oak Ridge, TN 37831, USA

$\uparrow$ Current address: Battelle Memorial Institute, Columbus, Ohio 43201

* Corresponding author: Frank E. Löffler. Center for Environmental Biotechnology, University of Tennessee, 676 Dabney Hall, 1416 Circle Drive, Knoxville, TN 37996-1605, USA

Competing Interest Statement: The authors declare no competing interest.

Classification: Biological Sciences (Major); Environmental Sciences (Minor)

Keywords: Dichloromethane fluxes, Degradation Potential, Bioremediation, Ozone Destruction

Anthropogenic activities and natural processes release dichloromethane (DCM), a toxic chemical with substantial ozone-depleting capacity. Specialized anaerobic bacteria metabolize DCM; however, the genetic basis for this process has remained elusive. Comparative genomics of the three known anaerobic DCM-degrading bacterial species revealed a homologous gene cluster, designated the methylene chloride catabolism $(m e c)$ gene cassette, comprising eight to ten genes with predicted 79.6 99.7\% amino acid identity. Functional annotation identified genes encoding a corrinoid-dependent 
26 methyltransferase system, and shotgun proteomics applied to two DCM-catabolizing cultures revealed

27 high expression of proteins encoded on the mec gene cluster during anaerobic growth with DCM. In a

28 DCM-contaminated groundwater plume, the abundance of mec genes strongly correlated with DCM

29 concentrations $\left(R^{2}=0.71-0.85\right)$ indicating their value as process-specific bioremediation biomarkers.

30 mec gene clusters were identified in metagenomes representing peat bogs, the deep subsurface, and

31 marine ecosystems including oxygen minimum zones (OMZs), suggesting DCM turnover in diverse

32 habitats. The broad distribution of anaerobic DCM catabolic potential suggests a relevant control function

33 for emissions to the atmosphere, and a role for DCM as a microbial energy source in critical zone

34 environments. The findings imply that the global DCM flux might be far greater than emission

35 measurements suggest.

37 Importance

38 Dichloromethane (DCM) is an increasing threat to stratospheric ozone with both anthropogenic and

39 natural emission sources. Anaerobic bacterial metabolism of DCM has not yet been taken into

40 consideration as a factor in the global DCM cycle. The discovery of the mec gene cassette associated

41 with anaerobic bacterial DCM metabolism and its widespread distribution in environmental systems

42 highlight a strong attenuation potential for DCM. Knowledge of the mec cassette offers new opportunities

43 to delineate DCM sources, enables more robust estimates of DCM fluxes, supports refined DCM emission

44 modeling and simulation of the stratospheric ozone layer, reveals a novel, ubiquitous $\mathrm{C}_{1}$ carbon metabolic

45 system, and provides prognostic and diagnostic tools supporting bioremediation of groundwater aquifers

46 impacted by DCM. 


\section{Introduction}

Dichloromethane (DCM, methylene chloride) is a widely distributed halomethane, produced both naturally and industrially. While anthropogenic DCM has received attention due to widespread groundwater contamination and, more recently ozone destruction potential, analysis of Antarctic ice cores has demonstrated that DCM was present in the atmosphere prior to the industrial era at approximately $10 \%$ of modern levels (Trudinger et al., 2004). The natural sources of DCM are diverse, encompassing both abiotic (Isidorov et al., 1990; Kanters \& Louw, 1996) and biotic (Eustáquio et al., 2008; Hoekstra et al., 1998; Wuosmaa \& Hager, 1990) processes and are estimated to contribute up to one third of total emissions (Gribble, 2010). Since the 1960's, atmospheric DCM concentrations rose steadily, with a mean annual increase of approximately $8 \%$ (Hossaini et al., 2017) although the reported worldwide production and use has been steady or declining since 2010 (McCulloch, 2017). Possible explanations include undocumented production, rogue emmissions, or increased natural emissions reflecting environmental (e.g., climate) change responses.

Atmospheric measurements and corresponding efforts to extrapolate to global-scale emissions have led

62 to the perception that marine systems and biomass combustion (e.g., wildfires) are the primary non-

63 industrial sources of DCM (Gribble, 2010), releasing estimated amounts of 190 and $60 \mathrm{Gg}$ of DCM each

64 year, respectively. Natural and deliberate forest fires have increased in frequency and size (Haines et al., 65 2020), a global trend that can be expected to lead to further formation of DCM. Wetlands emit up to $2 \mathrm{Gg}$ 66 DCM per year (Cox et al., 2004; Hu et al., 2017; Kolusu et al., 2018) (Supplementary Information), and 67 volcanic activity contributes an estimated amount of $0.021 \mathrm{Gg} / \mathrm{y}$ (Gribble, 2010). Halomethanes occur in 68 crustal minerals, and DCM release from rocks from the near-surface and deep subsurface have been 69 reported (Mulder et al., 2013; Svensen et al., 2009). Knowledge gaps remain and not-yet identified environmental sources of DCM are likely. The current understanding of global DCM fluxes, as opposed

71 to emissions, is very limited (Figure 1) (McCulloch, 2017). 


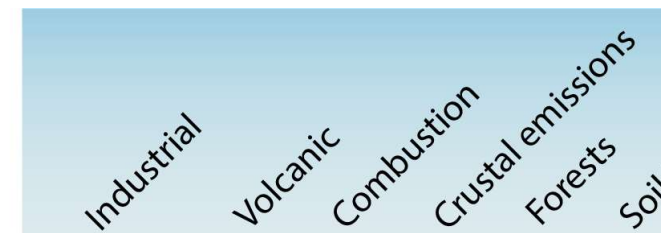

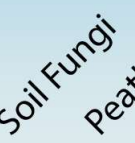

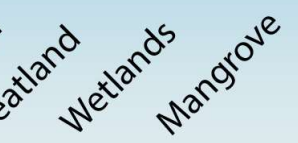

Gg DCM/yr

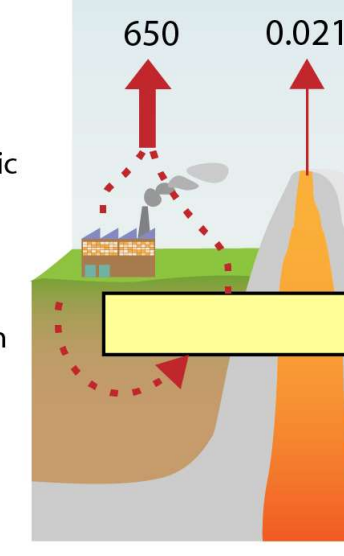
0.02160

?

?

$\begin{array}{lll}? & 1.4 & 1.5\end{array}$

.5

190

Atmospheric

Emissions

Biological Attenuation

Biotic and

Abiotic

Production

Figure 1. Major reported or potential DCM atmospheric emission sources. Width of the solid arrows is log-proportional to the magnitude of DCM emission estimates or potential. Dashed lines represent putative DCM sources, fluxes, and emissions that have not been directly investigated.

The rates of DCM production and consumption are unclear, and biological attenuation in anaerobic systems prior to release to the atmosphere has not been incorporated into existing atmospheric emission models (Hossaini et al., 2017).

Anaerobic metabolism of DCM was described in a bacterial isolate, Dehalobacterium formicoaceticum strain DMC (Defo) (19). Two additional bacterial populations responsible for DCM-metabolism in anaerobic enrichment cultures have been identified, 'Ca. Dichloromethanomonas elyunquensis' (Diel) (Justicia-Leon et al., 2012; Kleindienst et al., 2016, 2017) and 'Ca. Formimonas warabiya' (Dcmf) (Holland et al., 2021). All three DCM degraders are members of the family Peptococcaceae within the phylum Firmicutes. Bacterial dechlorination of DCM under oxic conditions is catalyzed by the glutathione-Stransferase (GST) DcmA (Muller et al., 2011); however, GST enzymes are generally absent in obligate anaerobes (Allocati et al., 2009). Accordingly, anaerobes metabolize DCM following a distinct strategy, in which the $C_{1}$ group is transferred to methylene-THF, a process that likely employs a corrinoid-dependent methyltransferase. The resulting methylene-THF is then channeled into the Wood-Ljungdahl pathway 
91 (WLP). Interestingly, Diel generates hydrogen during $\mathrm{DCM}$ mineralization to $\mathrm{CO}_{2}$ and chloride, which necessitates a syntrophic partnership with a hydrogen-consuming population (G. Chen, Kleindienst, et al., 2017). In contrast, 'Ca. Formimonas warabiya' ferments DCM via intracellular syntrophy to acetate and chloride (Holland et al., 2021; Wiechmann et al., 2020) and axenic Defo cultures ferment DCM to acetate, formate and chloride (G. Chen, Murdoch, et al., 2017).

Due to the genetic intractability of anaerobic DCM-degrading bacteria, comparative genomic approaches were applied to unravel underlying conserved genes involved in DCM metabolism, which led to discovery of a novel conserved gene cluster. Proteomics applied to Diel and Defo grown with DCM supported a role of this gene cluster in anaerobic DCM metabolism. Tracing this gene cluster by analyzing public metagenome datasets and performing targeted qPCR assays revealed the prevalence of this gene cassette and the potential DCM-metabolizing phenotype in various environmental systems. The findings suggest DCM formation and consumption in diverse natural ecosystems and provide new opportunities

104 for assessing how global changes in climate and habitat patterns impact DCM emissions and associated 105 ozone destruction.

\section{Methods}

\section{Comparative genomics}

109 Initial identification of homologous genes shared between the genomes of Diel and Defo was performed 110 by BLASTP-based reciprocal best hit $(\mathrm{RBH})$ analysis within the Integrated Microbial Genomes (IMG)

111 system (I.-M. A. Chen et al., 2019) and by using GView (Petkau et al., 2010). The two homologous gene 112 clusters present in the Diel genome were manually delineated. A homologous gene cluster was identified 113 in the genome of 'Ca. Formimonas warabiya' by application of local BLASTP searches (Altschul et al., 114 1990). Functional annotations (COG, pfam, KEGG, TIGRFAM) for Defo and Diel genes were obtained

115 from the IMG system, while those of ' $\mathrm{Ca}$. Formimonas warabiya' were assigned using the WebMGA 116 server (Wu et al., 2011) for COG (Tatusov et al., 2000), pfam (El-Gebali et al., 2019), and TIGRFAM (Haft 117 et al., 2012) annotations and GhostKOALA (Kanehisa et al., 2016) for KEGG annotations (Kanehisa et 118 al., 2017). 
Metagenome searches

121 All 18,314 metagenomes in the IMG database publicly available as of January 7, 2020 were subjected to

122 BLASTP query with the Defo MecE protein sequence with a minimum bit score cutoff of 150

123 (approximately 40\% identity). The resulting protein set was further filtered by applying a RBH criterion,

124 retaining only proteins whose closest BLAST-P hit to the IMG genomes database was found among the

125 MecE sequences located in the putative mec gene cassettes. The candidate metagenome MecE

126 homologs were then further filtered by retaining only proteins encoded by genes co-localized with at least

127 one other mec cassette protein, applying the same RBH criterion. All proteins encoded by genes located

128 on scaffolds where the mec protein homologs were identified were downloaded, subjected to local

129 BLASTP query using the ten mec gene cassette proteins from Defo, and plotted using GenoPlotR and

130 custom R scripts (Guy et al., 2010). Gene copy per genome for metagenome mec cassettes, provided in

131 Dataset S1, were calculated by dividing the read depth of the corresponding scaffold by an average read

132 depth of ten single copy conserved protein-encoding genes (ribosomal proteins L11 (COG0080), L1

133 (COG0081), L3 (COG0087), L4 (COG0088), L2 (COG0090), L22 (COG0091), L5 (COG0094), L15

134 (COG0200), L10 (COG0244), and L29 (COG0255)).

\section{Phylogenetic reconstruction}

137 The top 20 most similar proteins to each of the proteins encoded by each of the Defo genes located on

138 the mec cassette were obtained by searching the IMG genome database using BLASTP with a

139 confidence threshold of 1e-5, except in the case of MecC, for which the threshold was 1e-2. All mec

140 cassette genes located in both genomes and metagenomes were aligned and subjected to phylogenetic

141 reconstruction alongside the top 20 most similar genes located in microbial genomes in the IMG

142 database. Proteins encoded by genes from metagenomes were clustered at $80 \%$ similarity using CD-hit

143 (Li \& Godzik, 2006). Sequences were aligned using MAFFT G-INS-I with 1,000 maximum iterations

144 (Katoh \& Standley, 2013), trimmed using trimAl-gappyout (Capella-Gutiérrez et al., 2009) and subjected

145 to phylogenetic reconstruction using FastTree2 maximum-likelihood estimation (Gamma-LG model) (Price

146 et al., 2010). The resulting Newick tree files were visualized using the Interactive Tree of Life (Letunic \&

147 Bork, 2016). 
Preparation of Diel and Defo cultures for global proteomics

150 The DCM-degrading consortium RM harboring 'Ca. Dichloromethanomonas elyunquensis' (Diel) and the 151 axenic culture Dehalobacterium formicoaceticum (Defo) were grown in triplicate in $100 \mathrm{~mL}$ of anoxic

152 mineral basal salt medium with $0.2 \mathrm{mM}$ sodium sulfide, $0.2 \mathrm{mM} \mathrm{L-cysteine} \mathrm{(Löffler} \mathrm{et} \mathrm{al.,} \mathrm{2005)} \mathrm{and} 30$

$153 \mathrm{mM}$ bicarbonate $(\mathrm{pH} 7.3)$ under a headspace of $\mathrm{N}_{2} / \mathrm{CO}_{2}(80: 20$, vol/vol) with $156 \mu \mathrm{mol}(10 \mu \mathrm{L})$ of $\mathrm{DCM}$ as

154 the sole energy source. Cultures were initiated with a $5 \%(\mathrm{vol} / \mathrm{vol})$ inoculum, incubated at $30^{\circ} \mathrm{C}$ in the dark

155 without agitation, and provided one additional feeding of DCM once the initial amendment was consumed.

156 Biomass for (meta)proteomic analyses was collected after 2 weeks of incubation when approximately

$15795 \%$ of the second DCM feedings were consumed. Culture suspensions were passed through Sterivex ${ }^{\mathrm{TM}}$

$158 \quad 0.22 \mu \mathrm{m}$ membrane filter units (EMD Millipore Corporation, Billerica, MA, US) to capture cells. The outlet

159 of the filters were capped, and $1.5 \mathrm{~mL}$ of boiling SDS lysis buffer $(4 \%$ SDS in $100 \mathrm{mM}$ Tris/HCl buffer, $\mathrm{pH}$

160 8.0) were added to each of them. Filter unit inlets were then capped and placed in a laboratory rocker for

161 1-hour at room temperature. The SDS lysis buffer was removed by connecting $3 \mathrm{~mL}$ plastic syringes to

162 the inlets of the cartridges, and then holding the syringes and filter units vertically and pushing air into

163 each cartridge in order to withdraw as much lysate as possible by back pressure. In addition, filters were

164 rinsed once more with $0.5 \mathrm{~mL}$ of fresh SDS lysis buffer. Lysate mixtures were centrifuged at $21,000 \mathrm{~g}$ for

16515 mins and the clean protein supernatant transferred to fresh Eppendorf plastic tubes. Proteins were

166 precipitated with trichloroacetic acid (TCA), denaturated in $8 \mathrm{M}$ urea, reduced with dithiothreitol (DTT),

167 alkylated with iodoacetamide (IAM), and digested with sequencing grade trypsin (Promega, 1:50 trypsin-

168 to-protein [wt/wt]) (Yang et al., 2012). Protein concentrations were estimated with the BCA assay (Pierce

169 Biotechnology, Waltham, MA, US) and crude protein and peptide extracts were stored at $-80^{\circ} \mathrm{C}$ for

170 subsequent LC-MS/MS analysis.

171

172 Global proteomics analyses of Diel and Defo cultures

173 Global proteomics analyses were performed with an Orbitrap Q Exactive Plus mass spectrometer

174 (Thermo Fisher Scientific, Waltham, MA, US) equipped with a nano-electrospray source (ESI) interfaced

175 with a Proxeon EASY-nLC ${ }^{\text {TM }} 1200$ system. Peptides $(2 \mu \mathrm{g})$ from each sample were suspended in solvent 
$176 \mathrm{~A}(2 \%$ acetonitrile / $0.1 \%$ formic acid $)$ and injected onto a C18 resin $75 \mu \mathrm{m}$ microcapillary column $(1.7 \mu \mathrm{m}$,

$177100 \AA$, Phenomenex). Separation was accomplished at a constant flow rate of $250 \mathrm{~nL} / \mathrm{min}$ with a 90 -

178 minute gradient from 2 to $30 \%$ solvent B $(0.1 \%$ formic acid / $80 \%$ acetonitrile $)$ followed by an increase to

$17940 \%$ solvent B within 10 minutes. Tandem mass spectrometry data (MS/MS) were collected using the

180 Thermo Xcalibur software version 4.2.47 with similar parameters as reported before (Ganusova et al.,

181 2021). Raw spectral files were searched against protein databases from the IMG annotated genomes of

182 enrichment culture RM (which contains Diel) and Defo (IMG genome IDs 3300005804 and 2811995020 ,

183 respectively), to which common laboratory contaminant proteins were appended. For standard database

184 searching, the peptide MS/MS data was searched using Proteome Discoverer v2.4. The MS/MS data

185 were searched using the SEQUEST HT algorithm (Eng et al., 1994) which was configured to derive fully

186 tryptic peptides with the following settings: Maxium of 2 missed cleavage sites per peptide, minimum

187 peptide length of 2, MS1 mass tolerance of $10 \mathrm{ppm}$ and a MS2 tolerance of $0.02 \mathrm{Da}$. In addition,

188 carbamidomethylations on cysteines (+57.0214 Da) and methionine oxidations (+5.9949 Da) were

189 searched on peptides as static and dynamic modifications, respectively. Peptide spectrum match (PSM)

190 confidence was evaluated with Percolator (Käll et al., 2007). PSMs and peptides were considered

191 identified at a $q$ value of $<0.01$. Abundance values were converted to log2 values for ease of

192 visualization. The IMG gene IDs of detected culture RM proteins were mapped to proteins contained in

193 the IMG annotated genome of Diel (IMG genome ID 2627853586, Dataset S2).

DCM measurements

196 DCM was quantified by manual headspace injections $(0.1 \mathrm{~mL})$ into an Agilent 7890 gas chromatograph

197 (GC) (Santa Clara, CA, USA) equipped with a DB-624 column (60 m length, $0.32 \mathrm{~mm}$ i.d., $1.8 \mathrm{~mm}$ film

198 thickness) and a flame ionization detector (FID). To analyze DCM concentrations in groundwater, 1-mL

199 samples were collected, immediately transferred to sealed $20-\mathrm{mL}$ glass vials, and the DCM concentration

200 determined in the headspace. Aquoeus phase concentrations were determined using a dimensionless

201 Henry's law constant of 0.0895 (Gossett, 1987). 
Environmental samples

204 Anaerobic digester sludge was collected from two wastewater treatment plants, one located in Knoxville

205 (KUB) and the other in Lenoir City (LC), TN. Groundwater samples from six monitoring wells representing 206 within plume, fringe and outside locations at a DCM-contaminated site were obtained from CDM Smith

207 (Wright et al., 2017). The groundwater samples were shipped with an overnight carrier in a cooler with

208 ice and analyzed immediately upon receipt. Frank Stewart (Montana State University) provided archived

209 DNA samples from two vertical transcects from the ETNP OMZ.

\section{DCM enrichments}

212 Microcosms were established in $160-\mathrm{mL}$ glass serum bottles containing $98 \mathrm{~mL}$ of anoxic mineral basal

213 salt medium amended with $156 \mu \mathrm{mol}(10 \mu \mathrm{L})$ of DCM. The microcosms were seeded with $2 \mathrm{~mL}$ of

214 digester sludge, and additional DCM feedings occurred upon the depletion of DCM. Microcosms showing

215 DCM degradation were sequentially transferred to fresh anoxic medium with DCM as the sole electron

216 donor with an inoculation volume of $3 \mathrm{~mL}$. After eight consective transfers, solids-free enrichment cultures

217 were obtained that degraded DCM under anoxic conditions. DNA samples were extracted from the new

218 DCM enrichment cultures and used to examine the presence of mecE and mecF genes by qPCR.

DNA extraction

221 DNA extraction from $1 \mathrm{~mL}$ anaerobic digester sludge was performed using the DNeasy PowerSoil DNA

222 extraction kit (Qiagen, Valencia, CA). DNA from Defo and Diel cultures was extracted from $5 \mathrm{~mL}$ culture 223 suspensions collected onto $0.22 \mu \mathrm{m}$ Durapore membrane filters (Millipore, Cork, Ireland) and DNA using

224 the DNeasy PowerLyzer PowerSoil DNA extraction kit (Qiagen, Valencia, CA) following the 225 manufacturer's instructions.

227 Biomass from groundwater samples $(950 \mathrm{~mL})$ was collected on Supor® $0.2 \mu \mathrm{m}$ membrane filters (Pall 228 Lab., Ann Arbor, MI). Each filter was cut in half using a sterile scalpel and each piece was placed into a separate bead-beating tube for extraction with the DNeasy PowerLyzer PowerSoil DNA kit. The extracted 
230 DNA was concentrated with the Zymo DNA Clean and Concentrator-25 Kit (Zymo Research, Irvine, CA).

231 DNA concentrations were determined with fluorometry and DNA was stored at $-80^{\circ} \mathrm{C}$ until qPCR analysis.

233 Primer design, PCR and qPCR analyses

234 Primer sets were developed for both $m e c E$ and $m e c F$ genes. The design was based on the target gene

235 alleles identified in the genomes of Diel, Defo, Dcmf, and strain UNSWDHB and the most similar

236 homologs from peat bog metagenomes. Additional primers were designed based on the most common

237 mecE and mecF alleles identified in Eastern Pacific OMZ metagenomes (IMG genome Ga0066828, gene

238 IDs 100177932 [mecE] and 100027434 [mecF]). The respective target gene sequences were aligned

239 using ClustalW and primer sets were designed using the Primer 3 plug-in in Geneious R11.0.2 (Kearse et

240 al., 2012) for PCR and SYBR qPCR assays. The primer sequences were blasted against NCBI nr

241 database using the Primer BLAST program to verify specificity of the assays. The primers were obtained

242 from a commercial supplier (Integrated DNA Technologies, Coralville, IA). For quantification of total

243 bacterial 16S rRNA genes, previously reported Bac1055YF/Bac1392R (Ritalahti et al., 2006) and

244 EUB338F/EUB518R primers were used (Lane, 1991; Muyzer et al., 1993). Primer sequences are listed

245 in Table 1. 
Table 1. Novel primers used for qPCR. The column "Target" refers to the source of the template alleles used to design and validate the primers. peat; $m e c$ gene homologs derived from peat metagenomes.

\begin{tabular}{|c|c|c|c|c|}
\hline Assay & Primer & Sequence $\left(5^{\prime} \ldots . . .3^{\prime}\right)$ & Target & Reference \\
\hline qPCR & mecE $828 \mathrm{~F}$ & ACCATATTGTCTTTTTGCCYCAG & $\begin{array}{l}\text { Defo, Diel, Dcmf, Dehalobacter } \\
\text { UNSWDHB, and peat }\end{array}$ & this study \\
\hline qPCR & mecE 1007R & TACCGCCCAAATTTYTCTGC & $\begin{array}{l}\text { Defo, Diel, Dcmf, Dehalobacter } \\
\text { UNSWDHB, and peat }\end{array}$ & this study \\
\hline qPCR & mecF 554F & TGCTTGACATGGCCGTAMTGGAC & $\begin{array}{l}\text { Defo, Diel, Dcmf, Dehalobacter } \\
\text { UNSWDHB, and peat }\end{array}$ & this study \\
\hline qPCR & mecF $641 R$ & GCAGGATADCCATATTTGTCTTT & $\begin{array}{l}\text { Defo, Diel, Dcmf, Dehalobacter } \\
\text { UNSWDHB, and peat }\end{array}$ & this study \\
\hline qPCR & mecE 98F & ACGGCCTGACCTACAATGTC & ETNP OMZ samples & this study \\
\hline qPCR & mecE 191R & GCCGTGATGTCATAGCCGTA & ETNP OMZ samples & this study \\
\hline qPCR & mecF $612 F$ & GCTCAAGGACAAGTACGGCT & ETNP OMZ samples & this study \\
\hline qPCR & mecF $698 \mathrm{R}$ & CCGTATTGCTTCTTGCCGTG & ETNP OMZ samples & this study \\
\hline qPCR & EUB338F & ACTCCTACGGGAGGCAGCAG & All samples & 85 \\
\hline qPCR & EUB518R & ATTACCGCGGCTGCTGG & All samples & 86 \\
\hline qPCR & Bac1055YF & ATGGYTGTCGTCAGCT & All samples & 84 \\
\hline qPCR & Bac1392R & ACGGGCGGTGTGTAC & All samples & 84,85 \\
\hline
\end{tabular}

253 qPCR was performed in 10- $\mu \mathrm{L}$ volumes consisting of $5 \mu \mathrm{L} 2 \mathrm{X}$ Power SYBR Green PCR Master Mix

254 (Applied Biosystems, Foster City, CA), $0.5 \mu \mathrm{L}$ of each primer (final concentration of $300 \mathrm{nM}$ ) and $2 \mu \mathrm{L}$ of 255 template DNA (undiluted, 1:10 and 1:100 dilutions). qPCR analysis was conducted using a QuantStudio

256 12K Flex Real Time qPCR System (Life Technologies, Carlsbad, CA) and the thermocycling program was

257 followed as initial step of $10 \mathrm{~min}$ at $95^{\circ} \mathrm{C}, 40$ cycles of $15 \mathrm{sec}$ at $95^{\circ} \mathrm{C}$ and $1 \mathrm{~min}$ at $60^{\circ} \mathrm{C}$. Specific

258 amplification was confirmed by melt curve analysis and agarose gel electrophoresis as described (Hatt \&

259 Löffler, 2012). Standard curves were established with linear GeneArt DNA fragments of target genes.

260 Standards were run as triplicate on each plate using ten-fold dilution series in the range of $10^{1}$ to $10^{8}$ gene 
copies $/ \mu \mathrm{L}$. The amplification efficiencies, linear dynamic range, slope, $Y$-intercept and $R^{2}$ values are listed in Dataset S3. Amplification efficiencies (AE) were calculated using the equation 10(-1/slope) -1 .

\section{Metatranscriptomics}

265 Unprocessed Illumina metatranscriptome sequencing data generated from groundwater from a DCM

266 contamination plume was provided by CDM Smith. This same site was previously the subject of $16 \mathrm{~S}$

267 rRNA gene amplicon library analysis (Wright et al., 2017). Raw data were trimmed using Trimmomatic

268 v0.35 with a 6:25 sliding window quality trim, Illumina adapter read-through contamination removal, and

269 final minimum length of $25 \mathrm{bp}$ (Bolger et al., 2014). Trimmed reads were assembled de novo using Trinity

270 v2.8.5 under default parameters (Grabherr et al., 2011). Prokaryotic ribosomal RNA genes were detected

271 in the transcript contigs using barrnap v0.9-2 (Seeman, 2018) and removed using a custom R script

272 employing Biostrings v2.5.4 (Pagès et al., 2019). Remaining transcripts were queried against a database

273 consisting of all Defo mec genes using TBLASTX. Transcripts aligning to at least mecE with a bit-score

274 of $>1,000$ (approximately $70 \%$ full-length amino acid alignment) were included. Transcript coverage was

275 calculated using kallisto (Bray et al., 2016) and TPM values were calculated using the Trinity utility script

276 align_and_estimate_abundance.pl.

279 Results

280 Anaerobic DCM degraders share a common gene cassette

281 Comparative analysis of the Defo and Diel genomes revealed that the eight most similar genes (and 10 of

282 the top 25 most similar genes) in terms of percent predicted amino acid identity were located in genetic

283 clusters. The genome of Defo harbors a single 10-gene cluster and Diel has two highly similar clusters A

284 and B (Figure 2, Dataset S4). 


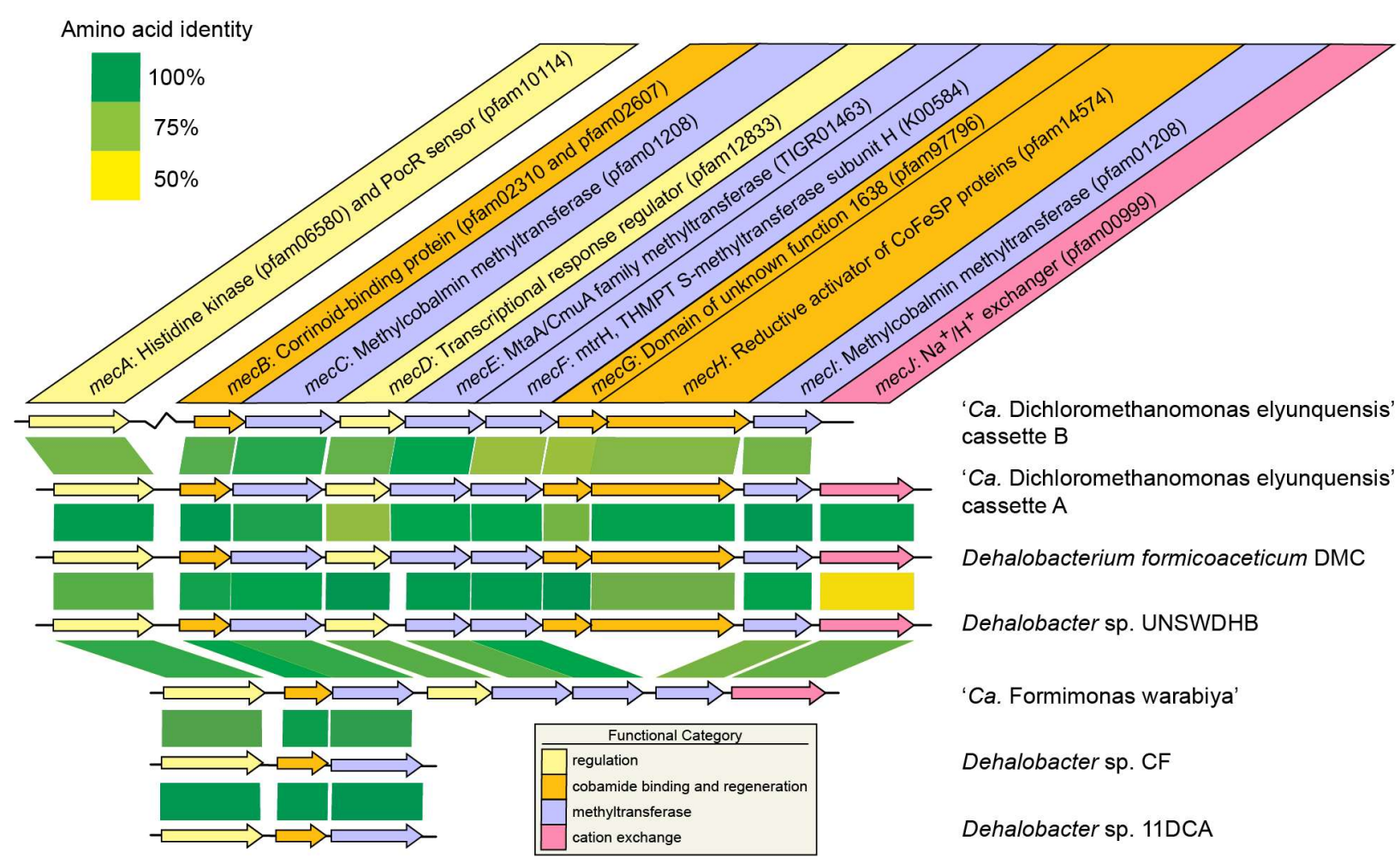

Figure 2. mec metabolic gene cassettes and close homologs identified in genomes. functional category of the encoded protein. Function was inferred from functional annotation systems, with priority given to the TIGRFAM and KEGG systems. GenoPlotR(26) was used to

292 The gene arrangement in these clusters is identical (i.e., syntenic) and predicted amino acid identities 293 between clusters range from $79.6 \%$ to $99.7 \%$ (Figure 2). This novel, conserved 10 -gene mec cassette

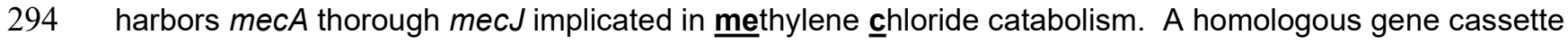
295 was also found in the newly described DCM degrader 'Ca. Formimonas warabiya' (Holland et al., 2019), 296 although lacking $m e c G$ and $m e c H$. Aside from mecJ, the only close homologs in any prokaryotic genome 297 to any of the mec-encoded proteins are found in the genomes of three chloroform degrading bacteria; a 298 homologous 10-gene cassette in Dehalobacter sp. strain UNSWDHB and partial gene cassettes in 299 Dehalobacter sp. strain CF and Dehalobacter sp. strain 1,1-DCA (Figure 2). Functional annotation of the 300 mec cassette gene products revealed a histidine kinase sensory protein and an associated regulatory 
301 protein (MecAD), an MtaA/CmuA methyltransferase (MecE), an MtrH methyltransferase (MecE), two

302 methyltransferases of indeterminate function ( $\mathrm{MecCl})$, a corrinoid-binding protein (MecB), a cation

303 transporter/antiporter (MecJ), a reductive activator of corrinoid proteins $(\mathrm{MecH})$, and a protein with a

304 conserved domain of unknown function (MecG) (Table 2 and Supplementary Text).

305

306

307

308

309

Table 2. Consensus functional annotations of the putative mec cassette gene product proteins.

COG, Clusters of Orthologous Genes; TIGRFAM, The Instutute for Genomic Research's

Database of Protein Families; pfam, Protein Familes; KEGG, Kyoto Encyclopedia of Genes and

Genomes.

\begin{tabular}{lll}
\hline Protein & Annotation & Description \\
\hline MecA & pfam06580 & histidine kinase \\
& pfam10114 & sensory domain found in PocR \\
MecB & COG5012 & methanogenic corrinoid protein MtbC1 \\
& pfam02310 & B12-binding \\
& pfam02607 & B12-binding 2 \\
& TIGR02370 & methyltransferase cognate corrinoid proteins \\
& K00548 & metH, 5-methyl-THF-homocysteine methyltransferase \\
MecC & COG0407 & uroporphyrinogen III decarboxylase \\
& pfam01208 & uroporphyrinogen decarboxylase \\
& K01599 & uroporphyrinogen decarboxylase \\
MecD & pfam00072 & translational response regulator receiver domain \\
& pfam12833 & helix-turn-helix domain \\
MecE & COG0407 & uroporphyrinogen III decarboxylase \\
& pfam01208 & uroporphyrinogen decarboxylase \\
& TIGR01463 & methyltransferase, MtaA/CmuA family \\
MecF & COG1962 & tetrahydromethanopterin S-methyltransferase, subunit H \\
& pfam02007 & MtrH, tetrahydromethanopterin S-methyltransferase subunit H \\
& TIGR01114 & N5-methyltetrahydromethanopterin:coenzyme M methyltransferase \\
& & subunit H \\
& K00584 & MtrH, tetrahydromethanopterin S-methyltransferase subunit H \\
MecG & pfam07796 & domain of unknown function 1638 \\
MecH & COG3894 & uncharacterized 2Fe-2 and 4Fe-4S clusters-containing protein \\
& pfam14574 & C-terminal of reductive activator of CoFeSP (RACo) \\
& pfam00111 & 2Fe-2S iron-sulfur cluster binding domain \\
Mecl & pfam01208 & uroporphyrinogen decarboxylase \\
& COG0475 & Kef-type K+ transport system, membrane component KefB \\
& pfam00999 & sodium/hydrogen exchanger family \\
& K03455 & monovalent cation:H+ antiporter-2, CPA2 family \\
& K03499 & KtrA, trk system potassium uptake protein \\
\hline & & \\
& &
\end{tabular}

310 
312 When grown with DCM, a total of 1,781 proteins were detected in the axenic Defo culture (Dataset S5)

313 and 1,743 proteins were detected in the metaproteome of mixed culture RM, 797 of which were assigned

314 to Diel (Dataset S2). The majority of proteins encoded by the mec gene cassettes were detected in the

315 proteomes of both DCM degraders (Figure 3, Table S1).

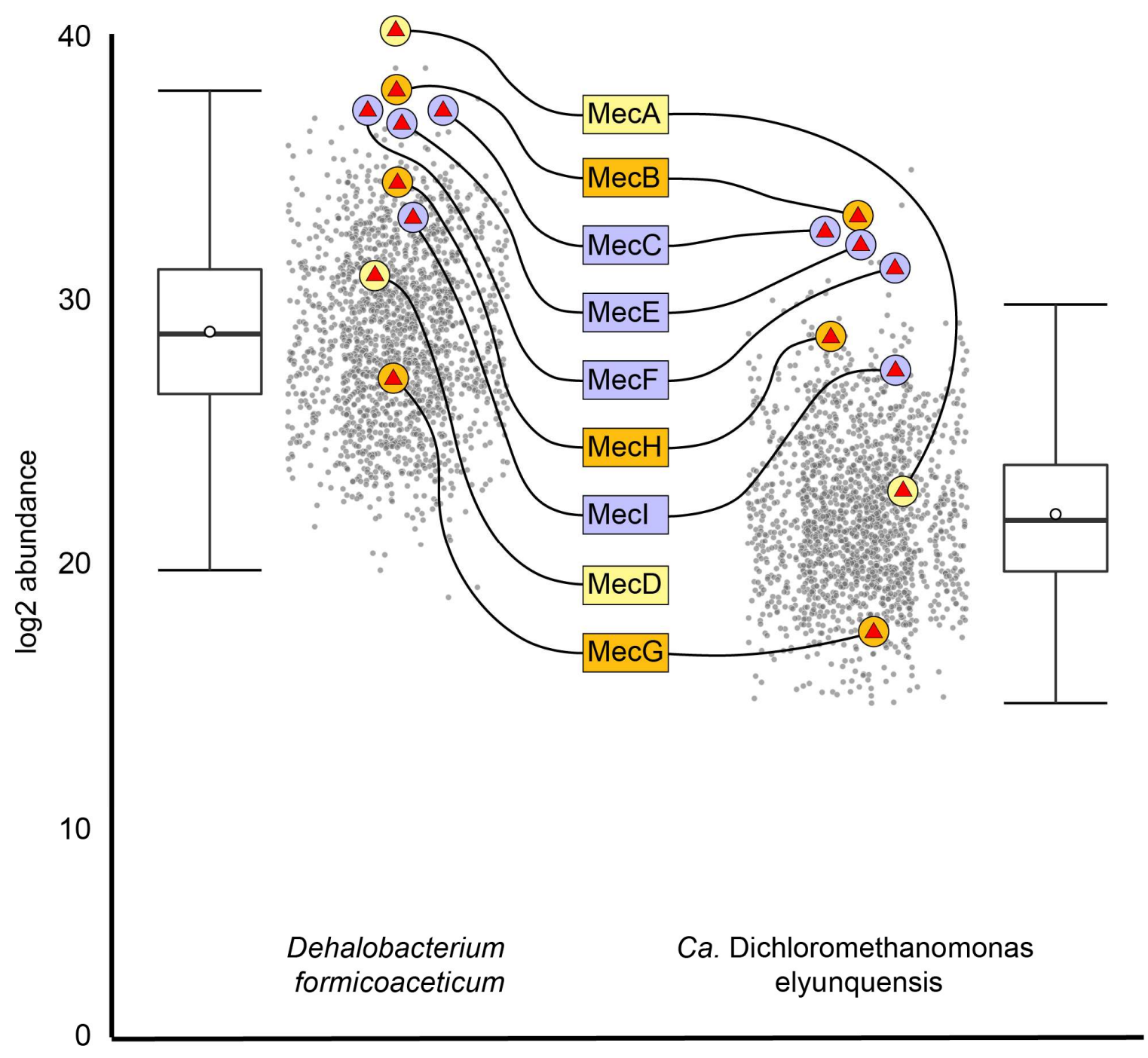
anaerobically with DCM as the sole carbon and energy source. Box and whisker plots show median (central horizontal line), upper and lower quartile range (box), highest and lowest values excluding outliers (upper and lower whiskers) and mean value (open circle). Protein products of 
the $m e c$ cassette genes are labelled, with general functional category indicated by color (orange, corrinoid-related; purple, methyltransferase; yellow, regulatory).

324 In Diel, all proteins of mec cassette B were detected except for MecD and MecJ while in Defo, all but

325 MecJ were detected. The corrinoid-binding protein MecB was the $2^{\text {nd }}$ and $3^{\text {rd }}$ most abundant protein in

326 Defo and Diel proteomes, respectively. The three methyltransferases MecC, MecE, and MecF were in

327 the top $1 \%$ most abundant proteins in both proteomes. The fourth methytransferase Mecl and the

328 corrinoid protein reductive activator $\mathrm{MecH}$ were all in the upper quartile of detected proteins. The sensor

329 histidine kinase MecA was $1^{\text {st }}$ and $38^{\text {th }}$ most abundant in Defo and Diel proteomes, respectively. In

330 neither case was $\mathrm{MecJ}$ detected, although its predicted eleven transmembrane alpha helices suggest

331 strong association with the cytoplasmic membrane, likely hindering detection in the proteomics

332 measurements (Vit \& Petrak, 2017).

334 DCM enriches for bacteria harboring mec genes

335 Targeted qPCR assays for the mecE and mecF genes did not yield quantifiable signals with template

336 DNA extracted from anaerobic digestor sludge. Following enrichment with DCM using the same

337 anaerobic sludge as inoculum, $1 \times 10^{6}$ to $5 \times 10^{7}$ gene copies $/ \mathrm{mL}$ of both $\mathrm{mec} E$ and $m e c F$ were measured

338 in transfer cultures, consistent with the observed consumption of DCM (Figure S1).

340 Groundwater samples from a DCM plume provided a unique opportunity to explore mec gene abundance

341 and expression in response to varying DCM concentrations. mecE- and mecF-targeted qPCR assays

342 yielded signals in a DCM dose-dependent manner, with ratios of mec gene copy number versus total

343 bacterial 16S rRNA gene copy numbers ranging between $4 \%$ and $10 \%$ in groundwater from wells with 3.2

$344 \mathrm{mg} / \mathrm{L}$ DCM or higher (Figure 4B). 


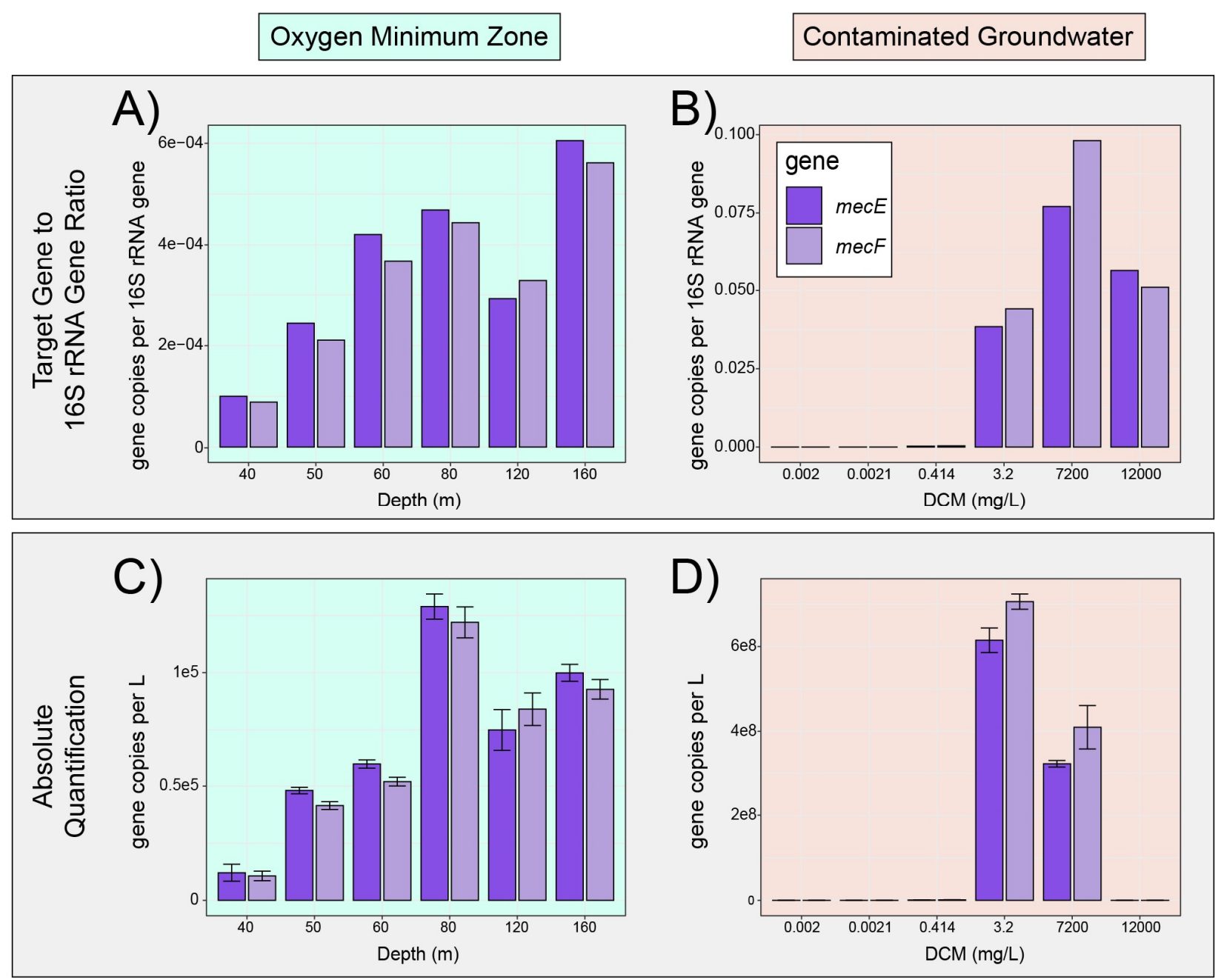

Figure 4. Quantitative PCR of $m e c E$ and $m e c F$ in the Eastern Pacific oxygen minimum zone (OMZ) and from groundwater samples from a DCM plume. A) and B) represent relative quantification results expressed as gene copies per 16S rRNA gene copy number for OMZ and DCM groundwater plume samples, respectively. Panels C) and D) represent absolute quantification (i.e., qPCR) results for $\mathrm{OMZ}$ and $\mathrm{DCM}$ groundwater plume

At lower DCM concentrations of $1.47 \mathrm{mg} / \mathrm{L}$, the relative abundance of mec genes dropped to $0.029 \%$, and in wells at the fringe of the plume with DCM in the low $\mu \mathrm{g} / \mathrm{L}$ range, mec gene to $16 \mathrm{~S}$ rRNA gene ratios

354 dropped to $0.0004-0.0026 \%$ (Figure 4B). Absolute mec gene copy numbers followed this trend, except

355 for samples collected from the well with the highest DCM concentration of $12 \mathrm{~g} / \mathrm{L}$, where lower abundances of bacterial and archaeal $16 \mathrm{~S}$ rRNA genes were observed (i.e., $1.44 \times 10^{6}$ versus $3.57 \times 10^{9}$ 
$357-1.60 \times 10^{10} 16 \mathrm{~S}$ rRNA genes per $\mathrm{L}$ at locations with lower DCM concentrations) (Figure 4D). Absolute

358 target gene copy numbers and ratios of target genes to total bacterial 16S rRNA copy numbers both

359 covaried with measured DCM concentrations, with no detections outside the plume and mec gene to $16 \mathrm{~S}$

360 rRNA gene ratios of up to $10 \%$ within the plume, indicating that roughly 1 in 10 bacterial genomes in the

361 plume harbored a mec cassette.

362

363 Analysis of metatranscriptomes, previously obtained for groundwater microbiomes collected from the

364 same DCM-contaminated site, revealed expression of mec cassette genes. mecE and mecF were

365 consistently identified on the same transcript, with relative expression reaching its highest value of 44.6

366 transcripts per million transcripts (TPM) in wells located in the plume fringes. mec cassette transcripts

367 were also detected in groundwater samples in the core plume at relative expression levels up to 21.2

368 TPM (Table S2).

369

370 Environmental distribution of the mec cassette

371 The search of over 18,000 metagenomes identified similar gene cassettes in 41 metagenomes from

372 peatland, the deep subsurface, and marine systems (Figure 5, Figure S2). The SI provides gene and

373 genome IDs and detailed BLAST-P results (Table S3, Dataset S6, Dataset S7). 


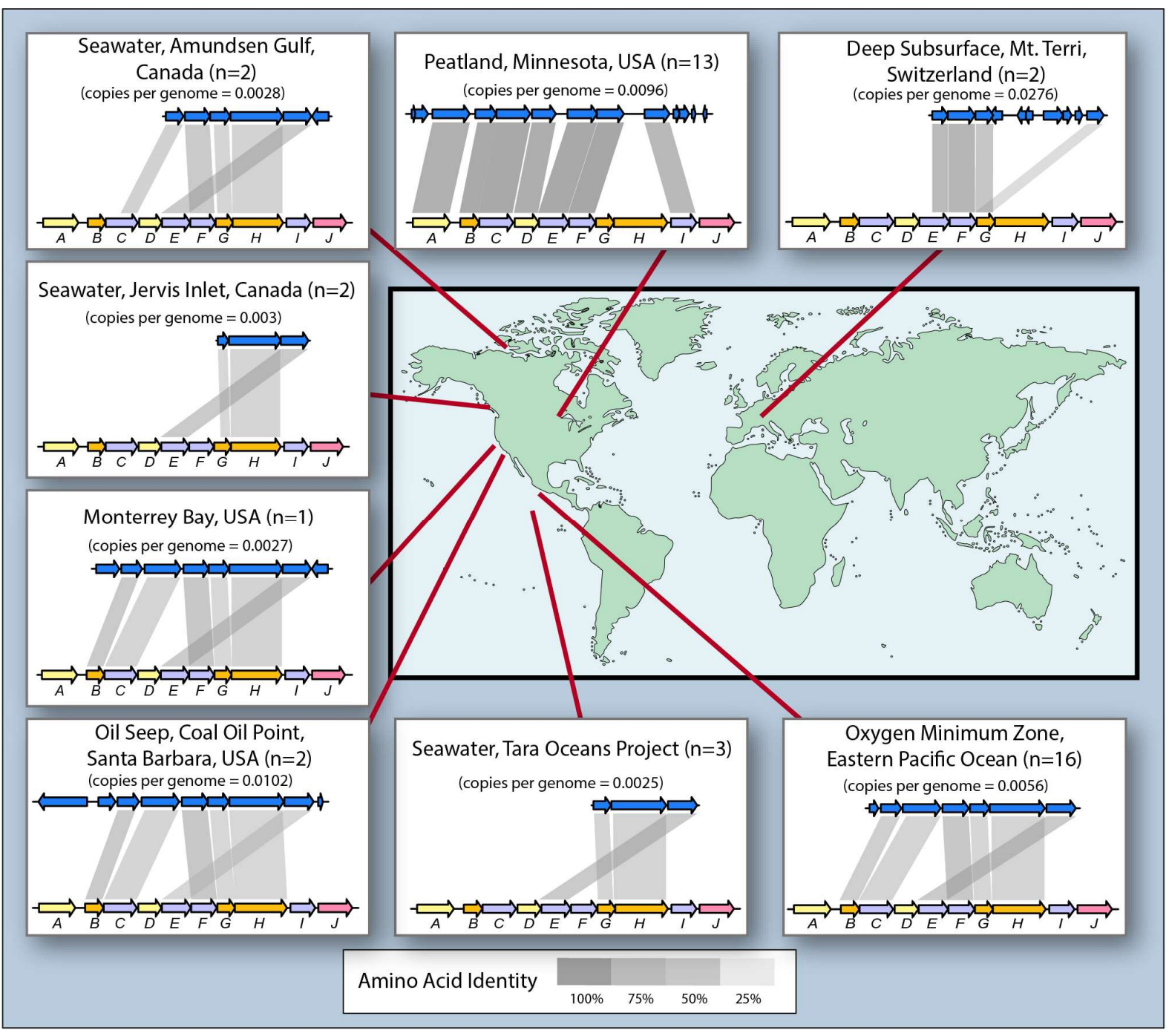

Figure 5. Distribution of 41 gene cassettes with homology and synteny to the Defo mec

cassette. Identified in the IMG metagenome database, details provided in Dataset S7.

Representative cassettes from the eight environments, in which the cassettes were identified, are derived. In each gene cassette illustration, the lower, multicolored gene cassette represents the found in the indicated environmental metagenome. " $n$ " indicates the number of individual samples, in which a syntenic cassette was identified, while "copies per genome" indicates the estimate of cassette copy per total genomes present in the metagenome, as determined by comparing cassette read depth to the average read depth of ten single-copy protein-encoding 
genes for the cassette shown. Shaded boxes show the BLAST-P-derived amino acid identity allowing comparisons of gene-product identities.

mec cassettes were identified in 13 of 117 metagenomes from ombrotrophic peat bogs in the Marcell experimental forest in Minnesota, USA. The mec cassettes were predominantly (i.e., 10 out of 13 gene cassettes) identified in metagenomes from samples collected between $1-1.5 \mathrm{~m}$ depth, where the $\mathrm{pH}$ was approximately 4.5 and anoxic conditions prevailed (Chris Schadt, personal communication). Two cassettes organized as mecABCDEFI displayed predicted amino acid identity scores to the Defo mec cassette genes above $80 \%$ (Figure 2) and close phylogenetic affiliation (Figure S3). This mecABCDEFI cassette was most prevalent, present in nearly $1 \%$ of all genome copies (i.e., approximately 1 out of 100 prokaryotic cells in the community harbor a mec cassette) (Dataset S7).

A total of 23 mec gene cassettes were identified in metagenomes from samples collected beneath the photic zone of the oceanic water column. The majority of cassettes was identified in metagenomes from

399 the Eastern Pacific oxygen minimum zone (OMZ) at depths of $150 \mathrm{~m}$ to $400 \mathrm{~m}$, wherein oxygen was 400 below the limit of detection (Thamdrup et al., 2019). Additional cassettes detected in metagenomes 401 derived from three coastal sites, Monterrey Bay, CA, Jervis Inlet in British Columbia, Canada, and 402 Amundsen Gulf, in Arctic northern Canada, and from an open ocean sample from the Eastern Tropical 403 North Pacific (ETNP). The marine mec cassettes were syntenic, with the order mecBCFGHE (Figure 5). $404 m e c E$ and $m e c F$ were the most similar to the corresponding Defo homologs, with average amino acid 405 identities of $49.7-51.6 \%$. All of the marine mec genes were more closely related to one another and to 406 the mec cassette genes of the characterized DCM degraders than to any other gene in assembled 407 metagenomes or genomes available in NCBI or the IMG database. The marine mec gene clusters 408 formed distinct, deeply branching clades (Figure S3). The highest marine mec cassette occurrence was 409 observed in a sample from Coal Oil Point, CA, a natural marine petroleum seep area (present in $1.02 \%$ of 410 total genome copies) (Dataset S7). qPCR applied to water column samples from two ETNP OMZ 411 locations detected mecE and mecF at a higher frequency (9 out of 11) than they were found in the ETNP 
412 OMZ metagenome assemblies (16 out of 90), with target gene-to-bacterial 16S rRNA gene ratios of 0.01

$413-0.06 \%$ (Figure 4, Dataset S8).

414

415 Evidence was obtained for the presence of mecEFG in anoxic porewater from a hydrogen-amended

416 borehole in Opalinus Clay rock situated $300 \mathrm{~m}$ beneath Mt. Terri, Switzerland (Bagnoud et al., 2016).

417 The amino acid identities for the putative methyltransferases MecE and MecF were 64.0 and $66.7 \%$,

418 respectively. Accordingly, phylogenetic analysis revealed close relationships with mecE and mecF of the

419 known DCM degraders (Figure S3). The deep subsurface mec cassettes were present in $2.8 \%$ of total

420 estimated genome copies.

Genomes of chloroform-respiring organisms harbor mec gene orthologs

423 The mec gene orthologs comprise cohesive, deeply branching clades (Figure S3). Aside from mecJ, no

424 close homologs (i.e., proteins with $>35 \%$ amino acid identity) to the mec genes are found in any publicly

425 available bacterial or archaeal genomes, with three notable exceptions. Homologs of $\operatorname{mec} A, \operatorname{mec} B$, and

$426 m e c C$ are found on genomes of the chloroform (CF) respirers Dehalobacter sp. strain CF and

427 Dehalobacter sp. strain 11DCA, both of which were reported to generate DCM as an end product during

428 growth with CF as electron acceptor (Grostern et al., 2010). In both of these genomes, the mecABC

429 homologs are found immediately adjacent to the CF reductive dehalogenase and anchor protein encoding

430 genes $\operatorname{cfr} A B$, suggesting functional association between the two gene clusters. In the third case, a

431 complete 10-gene mec cassette is located on the genome of Dehalobacter sp. strain UNSWDHB (Figure

432 2), also a CF-respiring organism that lacks the ability to utilize DCM (Wong et al., 2016). Close inspection

433 of the mec cassette of strain UNSWDHB reveals that mecE, implicated in the initial chloromethyltransfer

434 reaction, is truncated at the 5 ' end, which is projected to lead to a $\sim 70$ amino acid shorter protein (Figure

435 S4), consistent with a loss of function (Wong et al., 2016).

436

437 


\section{Discussion}

Identification DCM biomarker genes

440 The 10 gene mec cassette was initially identified by comparative genomic analyses between the

441 anaerobic DCM degrading bacteria Dehalobacterium formicoaceticum (Defo) and 'Ca.'

442 Dichloromethanomonas elyunquensis (Diel). A third highly similar and syntenic gene cassette was also

443 identified in the newer DCM degrader 'Ca.' Formamonas warabiya (Dcmf). This high degree of gene

444 identity and gene order among DCM degraders and the near total absence of any closely-related gene

445 cassette in any other bacterial genome placed strong suspicion on this gene cassette as being involved in

446 anaerobic DCM catabolism. To confirm the association of these genes with anaerobic growth on DCM,

447 additional enrichments were generated from municipal wastewater in Eastern Tennessee, which led to an

448 increase in the abundance of mec genes from undetectable to levels similar to those seen in Defo and

449 Diel cultures (1e6 to 1 e8 gene copies per $\mathrm{mL}$ ). Mec proteins were also among the most abundant

450 proteins in the proteomes of DCM-grown Defo and Diel. Furthermore, it was observed that mec genes

451 are enriched in the bacterial community at a DCM-contaminated groundwater site and were expressed in

452 proportion to DCM concentration. The multiple lines of evidence espouse a strong and exclusive

453 coordination between anaerobic DCM metabolism and mec cassette gene, transcript and protein

454 abundance.

Functional annotations of the mec cassette are consistent with a DCM dehalogenating methyltransferase

457 system

458 The DCM-degrading bacteria are strict anaerobes and no genes consistent with aerobic DCM catabolism

459 by a GST (e.g., dcmA) were identified in the genomes of strains Defo, Diel, or Dcmf. Previous

460 biochemical studies on Defo demonstrated that DCM is channeled into the WLP via methylene-THF

461 catalyzed by a corrinoid methyltransferase (G. Chen et al., 2018, 2020; A Mägli et al., 1998; Andreas

462 Mägli et al., 1996). Guided by functional annotation (Table 2) and comparison to analogous metabolic

463 systems, the proteins encoded by the mec cassette genes may comprise a DCM catabolic pathway that is

464 compatible with available biochemical evidence (Figure 6). 


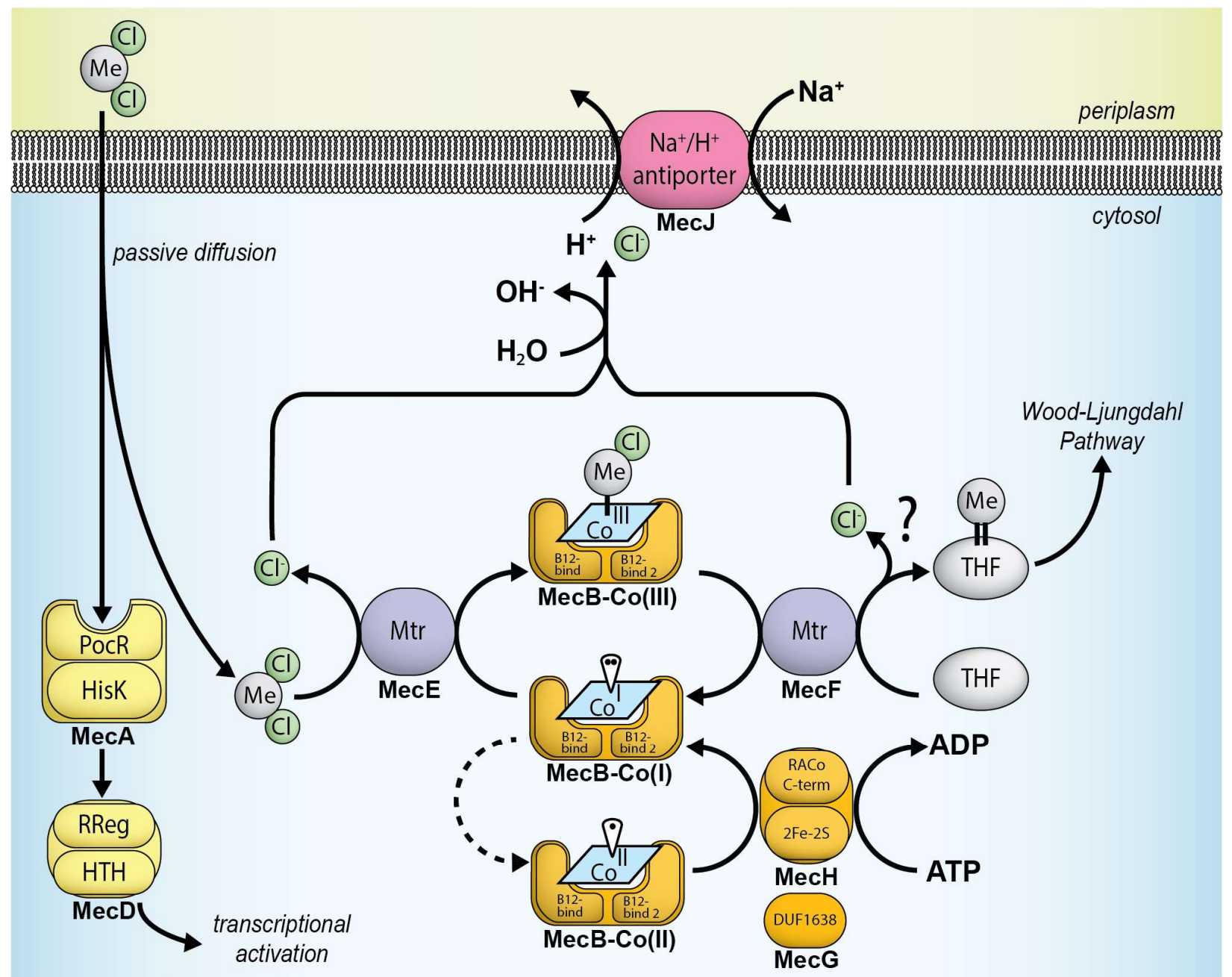

Figure 6. Proposed pathway for anaerobic DCM catabolism catalyzed by proteins encoded

by the $m e c$ cassette identified in this study. Proteins with regulatory (yellow),

methyltransferase (purple), B12-related (orange), transport (pink) functions are depicted. PocR, sensory domain found in PocR; HisK, histidine kinase; RReg, translational response regulator receiver domain; $\mathrm{HTH}$, helix-turn-helix domain; Mtr, methyltransferase; B12-bind, $\mathrm{B}_{12}$-binding domain; RACo, reductive activator of CoFeSP; THF, tetrahydrofolate. Mechanistic understanding about the release of the second chlorine substituent has not been obtained, as indicated by the question mark. Experimental CSIA data suggest that different mechanisms operate in different strains (40). 
476 The core system involved in $\mathrm{C}_{1}$ group transfer is likely composed of two methyltransferases, MecE and

477 MecF, and a corrinoid-binding protein, MecB. MecE is a member of the MtaA/CmuA family (TIGR01463),

478 an ortholog family defined by methylamine, methanol and chloromethane methyltransferases. The

479 relationship with such methyltransferases, especially the chloromethane dehalogenase CmuA of the

480 aerobic bacterium Hyphomicrobium sp. strain MC1 (Borodina et al., 2004), renders MecE a candidate for

481 catalyzing the initial chloromethyltransfer reaction to remove one chlorine substituent from DCM.

482 Chloromethane is dechlorinated by a corrinoid-dependent methyltransferase (CmuA), suggesting MecE

483 could perform an analogous single dechlorination of DCM during $\mathrm{C}_{1}$ group transfer to the corrinoid-

484 binding protein MecB. Such a reaction would yield a hypothetical chloromethyl corrinoid protein (Figure

485 6). Methyltransferase $\mathrm{MecF}$ is a member of the MtrH enzyme family responsible for transfer of a

486 corrinoid-bound methyl group to the organic methyl carrier tetrahydromethanopterin (THMPT), a cofactor

487 for $\mathrm{C}_{1}$ transfer analogous to tetrahydrofolate (THF). MecF is the best candidate for the final

488 methyltransfer reaction to THF generating methylene-THF, for which biochemical evidence exists (A

489 Mägli et al., 1998). This methyltransfer reaction could lead to C-Cl bond cleavage and release of the

490 second chlorine substituent. Alternatively, another methyltransferase, such as $\mathrm{MecC}$ or $\mathrm{Mecl}$, or another

491 enzyme not necessarily conserved among all anaerobic DCM degraders, is involved in the release of the

492 chlorine substitutent. Previously, $\mathrm{C}$ and $\mathrm{Cl}$ stable isotope measurements provided evidence for distinct

493 dechlorination mechanisms in anaerobic DCM degraders, and ${ }^{13} \mathrm{C}$-tracer experiments demonstrated

494 different end products, even though both Diel and Defo employ the WLP for DCM catabolism (G. Chen et

495 al., 2018, 2020).

497 Features of the remaining mec cassette gene products suggest roles in support of the dehalogenating $\mathrm{C}_{1}$ 498 group transfer system and gene expression regulation. MecGH share domain organization with proteins 499 implicated in activating the corrinoid-binding protein involved in methyltransferase-mediated methionine

500 synthesis in a variety of bacteria (Price et al., 2018). Thus, MecGH may function as a reductive activator

501 for MecB. MecJ is predicted to be a monovalent cation:proton antiporter, possibly supporting DCM

502 catabolism by maintaining acid-base homeostasis (E Pinner, 1994; Roosild et al., 2010), counteracting

503 acidification of the cytosol by hydrochloric acid (i.e., proton) generation during dechlorination of DCM 
504 (Ferguson et al., 2000). Co-localization of dehalogenase genes (e.g., reductive dehalogenases, haloacid

505 dehalogenases) and mecJ homologs is common among related organisms (Table S4), and the gene

506 cluster cmuABC for aerobic chloromethane utilization is $6 \mathrm{~kb}$ upstream and in the same orientation of a

507 gene (IMG ID 650984269) encoding a putative chloride carrier/channel (CIC) protein, a protein family also

508 implicated in acid-base homeostasis (lyer et al., 2002). The histidine kinase MecA likely represents a

509 DCM sensor kinase that regulates the DNA-binding protein MecD following detection of DCM via the

510 PocR domain (Anantharaman \& Aravind, 2005). The high abundance of MecA sensor kinase in Defo and

511 Diel proteomes ( $1^{\text {st }}$ and $38^{\text {th }}$ most abundant protein, respectively) may suggest an additional or alternative

512 role. In the marine $m e c$ cassettes, the regulatory genes $\operatorname{mec} A$ and $\operatorname{mec} D$ were not detected; however, in

513 two cases, homologs of $d c m R$, which encodes the DCM sensor and regulatory protein utilized by aerobic

514 DCM degraders (La Roche \& Leisinger, 1991), were identified directly adjacent to the mec cassette

515 (Figure 7) and could fulfill regulatory functions.

516 


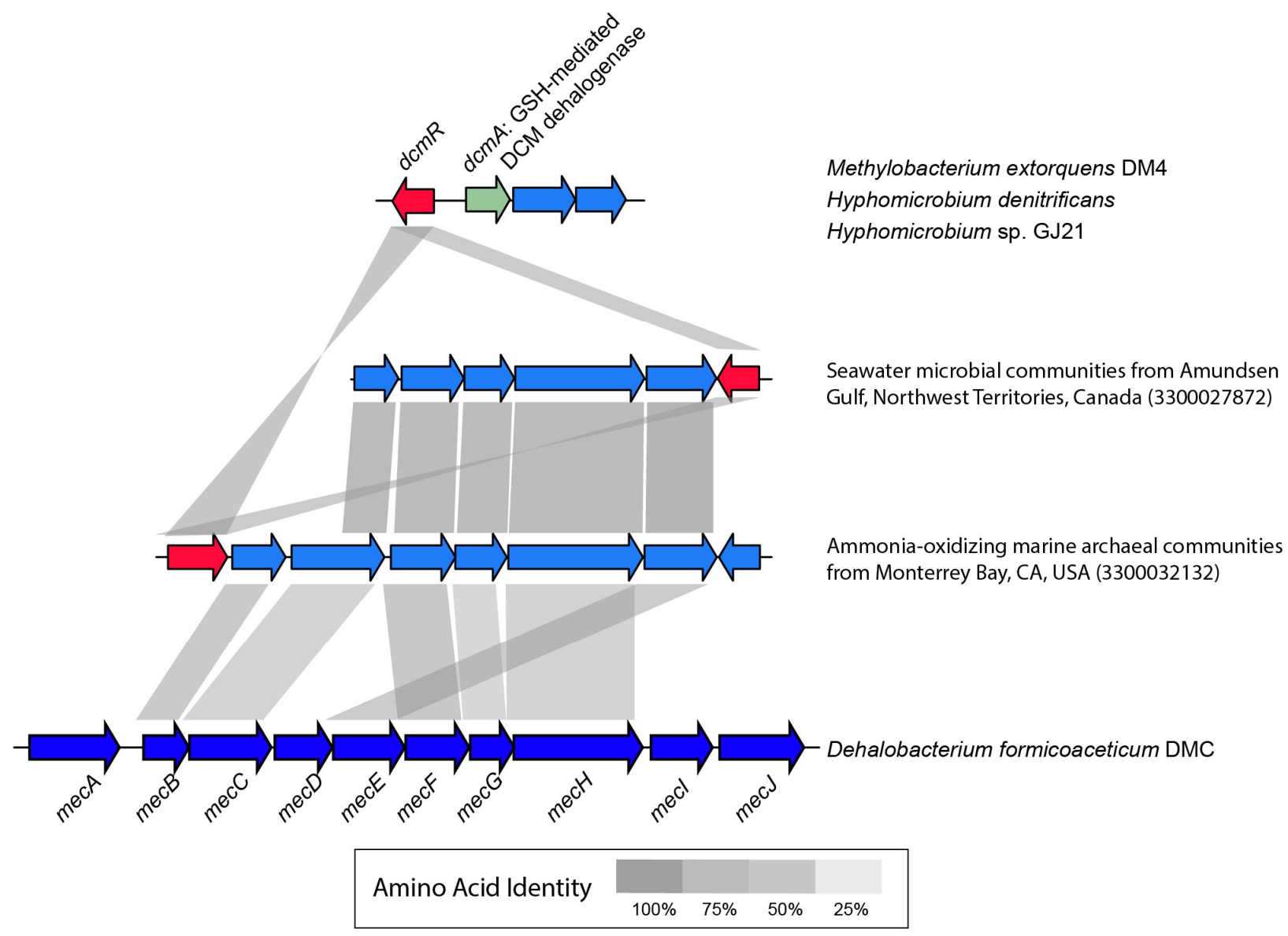

Figure 7. Two mec cassettes identified in metagenomes (from Monterrey Bay and Amundsen

Gulf, CA) are flanked by genes, colored red, encoding proteins annotated as DcmR sensory domain and regulator of DCM dehalogenase DcmA (KEGG K17071). The products of these genes share $70.6 \%$ amino acid identity and are $44.6 \%-46.4 \%$ identical to DcmR found in Methylbacterium extorquens strain DM4. The indicated gene cassette $(\operatorname{dcmRA})$ encodes

525 The proposed involvement of additional methyltransferases (i.e., MecC and $\mathrm{Mecl}$ ) is not unprecedented.

526 For example, the chloromethane utilization gene cluster in Hyphomicrobium sp. strain MC1 also contains 527 a third putative methyltransferase encoding gene, $c m u C$, which is required for growth with chloromethane 528 but whose function has yet to be revealed (Vannelli et al., 1999). Methanol-grown Desulfotmaculum kuznetsovii, which employs a similar methanol corrinoid methyltransferase system, also expresses three 
methyltransferases all located in the same gene cluster (Sousa et al., 2018). Additional details of the functional annotations of the mec cassette genes are provided in Supplementary Information.

533 Highly similar mec cassettes are broadly distributed in the environment. A search of public metagenomes

534 led to identification of mec cassettes in disparate ecosystems, including peatland, marine oxygen

535 minimum zones, and the deep subsurface. However, there is good reason to suspect each of these

536 environments as being hotspots for DCM flux. Peat bogs have been demonstrated to be rich in

537 chlorinated organic material (Biester et al., 2004) and have been identified as a source of halomethanes

538 (Dimmer et al., 2001). The occurrence of halomethanes in subsurface rock formations has been

539 demonstrated (Mulder et al., 2013), although information about quantities and fluxes is lacking.

540 Marine systems are net producers of DCM and considered major emitters to the atmosphere (Gribble,

$5412010)$. In the water column, DCM concentrations peak along with chlorophyll concentrations (Ooki \&

542 Yokouchi, 2011), consistent with production by phytoplankton and the abiotic chlorination of planktonic

543 iodo- and bromomethanes (Ooki \& Yokouchi, 2011). DCM is detected beneath the photic zone (Ooki \&

544 Yokouchi, 2011), suggesting that mixing events carry DCM into deeper waters, or other sources of DCM

545 exist in the deep ocean, possibly hydrothermal vents (Eklund et al., 1988; Isidorov et al., 1990; Jordan et

546 al., 2000) or settling dead biomass (Wever \& Barnett, 2017). Importantly, analysis of ETNP OMZ

547 samples using targeted qPCR assays led to much high detection rate ( 9 of 11) than was obtained by

548 metagenome analyses (16 of 90 ). This increase in frequency of detection is likely due to the higher

549 sensitivity of qPCR compared to shotgun metagenomics (Suttner et al., 2020) and implies that the mec

550 cassette is more broadly distributed in marine systems than the metagenomics survey results suggest.

552 Implications of widespread anaerobic DCM degradation potential

553 DCM predates the anthropocene and the mechanisms underlying natural releases are far from fully

554 characterized. Based on the available information, DCM is an energy source readily available to

555 microorganisms in various environments, and the anaerobic microbial consumption of DCM is likely a

556 major attenuation factor, eliminating DCM in anoxic systems prior to atmospheric release, and thus a

557 relevant process for reducing DCM emissions. Environmental change, including global warming, has 
high potential to alter the flux of DCM with unpredictable consequences for the integrity of the ozone layer. Whether low oxygen marine systems and peat bogs, for example, are net producers or net sinks of

560 DCM is currently unclear. OMZs are expanding at accelerating rates worldwide (Stramma et al., 2008),

561 and uncertainty exists over the impact of environmental change on net DCM emissions. Likewise, climate

562 change induced melting of permafrost in the northern hemisphere will create more active peat bogs, and

563 warming of peat bogs is expected to mobilize recalcitrant carbon and stimulate the breakdown of

564 accumulated organic materials (Gill et al., 2017), which will likely increase halomethane, including DCM

565 formation. As is the case with low oxygen marine systems, the degree to which DCM production is

566 counterbalanced by consumption in peat bogs is unknown. A widely distributed phenotype for anaerobic

567 DCM catabolism is likely to affect DCM pools, fluxes and thus the global DCM budget, which until present

568 considers atmospheric releases and abiotic stratospheric breakdown, but not microbial attenuation (i.e.,

569 sinks). The increased knowledge of microbial DCM catabolism offers opportunities to include relevant sink 570 and attenuation terms and generate refined flux models with more predictive power.

\section{Acknowledgments}

574 We thank F. Stewart and A. Bertagnolli for valuable discussions and providing Eastern Tropical North

575 Pacific Oxygen Minimum Zone DNA samples for qPCR analysis. T. Macbeth, K. Sorenson, and R.

576 Chenenko from CDM Smith graciously provided groundwater samples and metatranscriptomic data from

577 a DCM-contaminated site. The authors acknowledge N. Ivanova and R. Seshadri from the Joint Genome 578 Institute for providing invaluable insight into use of the IMG database.

Competing Interests: Authors declare that they have no competing interests.

581 Data and Code Availability: All genomes, genes, and protein sequences studied are available in the

582 IMG database (I.-M. A. Chen et al., 2019) under the specified ID numbers. Code used for data processing 583 and figure creation is available via RPubs links located in the methods section. All spectral data collected

584 from the Defo axenic cultures used in this study have been deposited in the MASSIVE and

585 ProteomeXchange repositories with identifiers MSV000087235 and PXD025479, respectively. Spectral 
data collected from the Diel axenic cultures used in this study have been deposited in the MASSIVE and ProteomeXchange repositories with identifiers MSV000086520 and PXD022742, respectively. Scripts used to perform gene copy per genome copy calculations, pairwise gene cassette alignments, and to construct gene cassette synteny plots can be found at https://rpubs.com/rmurdoch/mec cassette abundance and synteny. Detailed description of gene phylogeny pipelines can be found at https://rpubs.com/rmurdoch/mec cassette trees. Full metatranscriptome analysis pipeline description and scripts used to operate programs can be found at https://rpubs.com/rmurdoch/mec transcriptomes.

\section{References}

Allocati, N., Federici, L., Masulli, M., \& Di llio, C. (2009). Glutathione transferases in bacteria. In FEBS Journal (Vol. 276, Issue 1, pp. 58-75). John Wiley \& Sons, Ltd. https://doi.org/10.1111/j.17424658.2008.06743.x

Altschul, S. F., Gish, W., Miller, W., Myers, E. W., \& Lipman, D. J. (1990). Basic local alignment search tool. Journal of Molecular Biology, 215(3), 403-410. https://doi.org/10.1016/S0022-2836(05)80360-2

Anantharaman, V., \& Aravind, L. (2005). MEDS and PocR are novel domains with a predicted role in sensing simple hydrocarbon derivatives in prokaryotic signal transduction systems. Bioinformatics, 21(12), 2805-2811. https://doi.org/10.1093/bioinformatics/bti418

Bagnoud, A., Chourey, K., Hettich, R. L., de Bruijn, I., Andersson, A. F., Leupin, O. X., Schwyn, B., \& Bernier-Latmani, R. (2016). Reconstructing a hydrogen-driven microbial metabolic network in Opalinus Clay rock. Nature Communications, 7(1), 12770. https://doi.org/10.1038/ncomms12770

Biester, H., Keppler, F., Putschew, A., Martinez-Cortizas, A., \& Petri, M. (2004). Halogen retention, organohalogens, and the role of organic matter decomposition on halogen enrichment in two Chilean peat bogs. Environmental Science and Technology, 38(7), 1984-1991. https://doi.org/10.1021/es0348492

Bolger, A. M., Lohse, M., \& Usadel, B. (2014). Trimmomatic: a flexible trimmer for Illumina sequence data. Bioinformatics, 30(15), 2114-2120. https://doi.org/10.1093/bioinformatics/btu170

Borodina, E., McDonald, I. R., \& Murrell, J. C. (2004). Chloromethane-dependent expression of the cmu gene cluster of Hyphomicrobium chloromethanicum. Applied and Environmental Microbiology, 70(7), 4177-4186. https://doi.org/10.1128/AEM.70.7.4177-4186.2004

Bray, N. L., Pimentel, H., Melsted, P., \& Pachter, L. (2016). Near-optimal probabilistic RNA-seq quantification. Nature Biotechnology, 34(5), 525-527. https://doi.org/10.1038/nbt.3519

Capella-Gutiérrez, S., Silla-Martínez, J. M., \& Gabaldón, T. (2009). trimAl: a tool for automated alignment trimming in large-scale phylogenetic analyses. Bioinformatics (Oxford, England), 25(15), 19721973. https://doi.org/10.1093/bioinformatics/btp348

Chen, G., Fisch, A. R., Gibson, C. M., Mack, • E Erin, Seger, • Edward S, Campagna, S. R., Frank, •, \& Löffler, E. (2020). Mineralization versus fermentation: evidence for two distinct anaerobic bacterial degradation pathways for dichloromethane. The ISME Journal, 14, 959-970. https://doi.org/10.1038/s41396-019-0579-5

Chen, G., Kleindienst, S., Griffiths, D. R., Mack, E. E., Seger, E. S., \& Löffler, F. E. (2017). Mutualistic interaction between dichloromethane- and chloromethane-degrading bacteria in an anaerobic mixed culture. Environmental Microbiology, 19(11), 4784-4796. https://doi.org/10.1111/1462-2920.13945

Chen, G., Murdoch, R. W., Mack, E. E., Seger, E. S., \& Löffler, F. E. (2017). Complete genome sequence of Dehalobacterium formicoaceticum strain DMC, a strictly anaerobic dichloromethane-degrading 
662

663

664

665

666

667

668

669

670

671

672

673

674

675

676

677

678

679

680

681

682

683

684

685

686

bacterium. Genome Announcements, 5(37). https://doi.org/10.1128/genomeA.00897-17

Chen, G., Shouakar-Stash, O., Phillips, E., Justicia-Leon, S. D., Gilevska, T., Sherwood Lollar, B., Mack, E. E., Seger, E. S., \& Löffler, F. E. (2018). Dual carbon-chlorine isotope analysis indicates distinct anaerobic dichloromethane degradation pathways in two members of Peptococcaceae. Environmental Science \& Technology, 52(15), 8607-8616. https://doi.org/10.1021/acs.est.8b01583

Chen, I.-M. A., Chu, K., Palaniappan, K., Pillay, M., Ratner, A., Huang, J., Huntemann, M., Varghese, N., White, J. R., Seshadri, R., Smirnova, T., Kirton, E., Jungbluth, S. P., Woyke, T., Eloe-Fadrosh, E. A., Ivanova, N. N., \& Kyrpides, N. C. (2019). IMG/M v.5.0: an integrated data management and comparative analysis system for microbial genomes and microbiomes. Nucleic Acids Research, 47(D1), D666-D677. https://doi.org/10.1093/nar/gky901

Cox, M. L., Fraser, P. J., Sturrock, G. A., Siems, S. T., \& Porter, L. W. (2004). Terrestrial sources and sinks of halomethanes near Cape Grim, Tasmania. Atmospheric Environment, 38(23), 3839-3852. https://doi.org/10.1016/J.ATMOSENV.2004.03.050

Dimmer, C. H., Simmonds, P. G., Nickless, G., \& Bassford, M. R. (2001). Biogenic fluxes of halomethanes from Irish peatland ecosystems. Atmospheric Environment, 35(2), 321-330. https://doi.org/10.1016/S1352-2310(00)00151-5

E Pinner, E. P. and S. S. (1994). Kinetic properties of NhaB, a Na+/H+ antiporter from Escherichia coli. The Journal of Biological Chemistry, 269, 26274-26279. http://www.jbc.org/content/268/8/5382?ijkey=264978fabe3ca92c7251ed45ef58e1776e4abe69\&keyt ype2=tf_ipsecsha

Eklund, G., Pedersen, J. R., \& Stromberg, B. (1988). Methane, hydrogen chloride and oxygen form a wide range of chlorinated organic species in the temperature range $400^{\circ} \mathrm{C}-950^{\circ} \mathrm{C}$. Chemosphere, 17(3), 575-586.

El-Gebali, S., Mistry, J., Bateman, A., Eddy, S. R., Luciani, A., Potter, S. C., Qureshi, M., Richardson, L. J., Salazar, G. A., Smart, A., Sonnhammer, E. L. L., Hirsh, L., Paladin, L., Piovesan, D., Tosatto, S. C. E., \& Finn, R. D. (2019). The Pfam protein families database in 2019. Nucleic Acids Research, 47, D427-D432. https://doi.org/10.1093/nar/gky995

Eng, J. K., McCormack, A. L., \& Yates, J. R. (1994). An approach to correlate tandem mass spectral data of peptides with amino acid sequences in a protein database. Journal of the American Society for Mass Spectrometry, 5(11), 976-989. https://doi.org/10.1016/1044-0305(94)80016-2

Eustáquio, A. S., Pojer, F., Noel, J. P., \& Moore, B. S. (2008). Discovery and characterization of a marine bacterial SAM-dependent chlorinase. Nature Chemical Biology, 4(1), 69-74. https://doi.org/10.1038/nchembio.2007.56

Ferguson, G. P., Booth, I. R., Evans, G. J., \& Vuilleumier, S. (2000). Growth inhibition of Escherichia coli by dichloromethane in cells expressing dichloromethane dehalogenase/glutathione S-transferase. Microbiology, 146(11), 2967-2975. https://doi.org/10.1099/00221287-146-11-2967

Ganusova, E. E., Vo, L. T., Abraham, P. E., O’Neal Yoder, L., Hettich, R. L., \& Alexandre, G. (2021). The Azospirillum brasilense core chemotaxis proteins CheA1 and CheA4 link chemotaxis signaling with nitrogen metabolism. MSystems, 6(1). https://doi.org/10.1128/msystems.01354-20

Gill, A. L., Giasson, M.-A., Yu, R., \& Finzi, A. C. (2017). Deep peat warming increases surface methane and carbon dioxide emissions in a black spruce-dominated ombrotrophic bog. Global Change Biology, 23(12), 5398-5411. https://doi.org/10.1111/gcb.13806

Gossett, J. M. (1987). Measurement of Henry's Law constants for C1 and C2 chlorinated hydrocarbons. Environmental Science and Technology, 21(2), 202-208. https://doi.org/10.1021/es00156a012

Grabherr, M. G., Haas, B. J., Yassour, M., Levin, J. Z., Thompson, D. A., Amit, I., Adiconis, X., Fan, L., Raychowdhury, R., Zeng, Q., Chen, Z., Mauceli, E., Hacohen, N., Gnirke, A., Rhind, N., Di Palma, F., Birren, B. W., Nusbaum, C., Lindblad-Toh, K., ... Regev, A. (2011). Full-length transcriptome assembly from RNA-Seq data without a reference genome. Nature Biotechnology, 29(7), 644-652. https://doi.org/10.1038/nbt.1883

Gribble, G. W. (2010). Naturally Occurring Organohalogen Compounds - A Comprehensive Update (Vol. 91). Springer Vienna. https://doi.org/10.1007/978-3-211-99323-1

Grostern, A., Duhamel, M., Dworatzek, S., \& Edwards, E. A. (2010). Chloroform respiration to dichloromethane by a Dehalobacter population. Environmental Microbiology, 12(4), 1053-1060. https://doi.org/10.1111/j.1462-2920.2009.02150.x

Guy, L., Roat Kultima, J., \& Andersson, S. G. E. (2010). genoPlotR: comparative gene and genome visualization in R. Bioinformatics, 26(18), 2334-2335. https://doi.org/10.1093/bioinformatics/btq413 
Haft, D. H., Selengut, J. D., Richter, R. A., Harkins, D., Basu, M. K., \& Beck, E. (2012). TIGRFAMs and Genome Properties in 2013. Nucleic Acids Research, 41(D1), D387-D395. https://doi.org/10.1093/nar/gks1234

Haines, A., Ebi, K. L., Ph, D., Li, S., \& Ph, D. (2020). Wildfires, global climate change, and human health. The New England Journal of Medicine, 383, 2173-2181.

Hatt, J. K., \& Löffler, F. E. (2012). Quantitative real-time PCR (qPCR) detection chemistries affect enumeration of the Dehalococcoides 16S rRNA gene in groundwater. Journal of Microbiological Methods, 88(2), 263-270. https://doi.org/10.1016/j.mimet.2011.12.005

Hoekstra, E. J., M Verhagen, F. J., Field, J. A., B De Leer, E. W., \& Th Brinkman, U. A. (1998). Natural production of chloroform by fungi. Phytochemistry, 49(1), 91-97.

Holland, S. I., Edwards, R. J., Ertan, H., Wong, Y. K., Russell, T. L., Deshpande, N. P., Manefield, M., \& Lee, M. J. (2019). Whole genome sequencing of a novel, dichloromethane-fermenting Peptococcaceae from an enrichment culture. PeerJ, 7, e7775. https://doi.org/10.7287/peerj.preprints.27718v1

Holland, S. I., Ertan, H., Montgomery, K., Manefield, M. J., \& Lee, M. (2021). Novel dichloromethanefermenting bacteria in the Peptococcaceae family. The ISME Journal, 15, 1709-1721. https://doi.org/10.1038/s41396-020-00881-y

Hossaini, R., Chipperfield, M. P., Montzka, S. A., Leeson, A. A., Dhomse, S. S., \& Pyle, J. A. (2017). The increasing threat to stratospheric ozone from dichloromethane. Nature Communications, 8(1), 15962. https://doi.org/10.1038/ncomms15962

Hu, S., Niu, Z., Chen, Y., Li, L., \& Zhang, H. (2017). Global wetlands: Potential distribution, wetland loss, and status. Science of The Total Environment, 586, 319-327. https://doi.org/10.1016/J.SCITOTENV.2017.02.001

Isidorov, V. A., Zenkevich, I. G., \& loffe, B. V. (1990). Volatile organic compounds in solfataric gases. Journal of Atmospheric Chemistry, 10, 329. https://link.springer.com/content/pdf/10.1007\%2FBF00053867.pdf

Iyer, R., Iverson, T. M., Accardi, A., \& Miller, C. (2002). A biological role for prokaryotic CIC chloride channels. Nature, 419(6908), 715-718. https://doi.org/10.1038/nature01000

Jordan, A., Harnisch, J., Borchers, R., Le Guern, F., \& Shinohar, H. (2000). Volcanogenic halocarbons. Environmental Science \& Technology, 34(6), 1122-1124. https://doi.org/10.1021/ES990838Q

Justicia-Leon, S. D., Ritalahti, K. M., Mack, E. E., \& Löffler, F. E. (2012). Dichloromethane fermentation by a Dehalobacter sp. in an enrichment culture derived from pristine river sediment. Applied and Environmental Microbiology, 78(4), 1288-1291. https://doi.org/10.1128/AEM.07325-11

Käll, L., Canterbury, J. D., Weston, J., Noble, W. S., \& MacCoss, M. J. (2007). Semi-supervised learning for peptide identification from shotgun proteomics datasets. Nature Methods, 4(11), 923-925. https://doi.org/10.1038/nmeth1113

Kanehisa, M., Furumichi, M., Tanabe, M., Sato, Y., \& Morishima, K. (2017). KEGG: new perspectives on genomes, pathways, diseases and drugs. Nucleic Acids Research, 45(D1), D353-D361. https://doi.org/10.1093/nar/gkw1092

Kanehisa, M., Sato, Y., \& Morishima, K. (2016). BlastKOALA and GhostKOALA: KEGG tools for functional characterization of genome and metagenome sequences. Journal of Molecular Biology, 428(4), 726-731. https://doi.org/10.1016/j.jmb.2015.11.006

Kanters, J., \& Louw, R. (1996). Thermal and catalysed halogenation in combustion reactions. Chemosphere, 32(1), 89-97. https://doi.org/10.1016/0045-6535(95)00230-8

Katoh, K., \& Standley, D. M. (2013). MAFFT multiple sequence alignment software version 7: improvements in performance and usability. Molecular Biology and Evolution, 30(4), 772-780. https://doi.org/10.1093/molbev/mst010

Kearse, M., Moir, R., Wilson, A., Stones-Havas, S., Cheung, M., Sturrock, S., Buxton, S., Cooper, A., Markowitz, S., Duran, C., Thierer, T., Ashton, B., Meintjes, P., Drummond, A., \& Valencia, A. (2012). Geneious Basic: An integrated and extendable desktop software platform for the organization and analysis of sequence data. Bioinformatics (Oxford, England), 28(12), 1647-1649. https://doi.org/10.1093/bioinformatics/bts199

Kleindienst, S., Higgins, S. A., Tsementzi, D., Chen, G., Konstantinidis, K. T., Mack, E. E., \& Löffler, F. E. (2017). ' Candidatus Dichloromethanomonas elyunquensis' gen. nov., sp. nov., a dichloromethanedegrading anaerobe of the Peptococcaceae family. Systematic and Applied Microbiology, 40(3), 150-159. https://doi.org/10.1016/j.syapm.2016.12.001 
Kleindienst, S., Higgins, S. A., Tsementzi, D., Konstantinidis, K. T., Mack, E. E., \& Löffler, F. E. (2016). Draft genome sequence of a strictly anaerobic dichloromethane-degrading bacterium. Genome Announcements, 4(2), e00037-16. https://doi.org/10.1128/GENOMEA.00037-16

Kolusu, S. R., Schlünzen, K. H., Grawe, D., \& Seifert, R. (2018). Determination of chloromethane and dichloromethane in a tropical terrestrial mangrove forest in Brazil by measurements and modelling. Atmospheric Environment, 173, 185-197. https://doi.org/10.1016/J.ATMOSENV.2017.10.057

La Roche, S. D., \& Leisinger, T. (1991). Identification of dcmR, the regulatory gene governing expression of dichloromethane dehalogenase in Methylobacterium sp. strain DM4. Journal of Bacteriology, 173(21), 6714-6721. http://jb.asm.org/

Lane, D. J. (1991). 16S/23S rRNA sequencing. In Stackebrandt \& M. Goodfellow (Eds.), Nucleic acid techniques in bacterial systematics (pp. 115-175). John Wiley \& Sons, Ltd.

Letunic, I., \& Bork, P. (2016). Interactive tree of life (iTOL) v3: an online tool for the display and annotation of phylogenetic and other trees. Nucleic Acids Research, 44(W1), W242-W245. https://doi.org/10.1093/nar/gkw290

Li, W., \& Godzik, A. (2006). Cd-hit: a fast program for clustering and comparing large sets of protein or nucleotide sequences. Bioinformatics, 22(13), 1658-1659. https://doi.org/10.1093/bioinformatics/btl158

Löffler, F. E., Sanford, R. A., \& Ritalahti, K. M. (2005). Enrichment, cultivation, and detection of reductively dechlorinating bacteria. Methods in Enzymology, 397, 77-111. https://doi.org/10.1016/S00766879(05)97005-5

Mägli, A, Messmer, M., \& Leisinger, T. (1998). Metabolism of dichloromethane by the strict anaerobe Dehalobacterium formicoaceticum. Applied and Environmental Microbiology, 64(2), 646-650. http://www.ncbi.nlm.nih.gov/pubmed/16349505

Mägli, Andreas, Wendt, M., \& Leisinger, T. (1996). Isolation and characterization of Dehalobacterium formicoaceticum gen. nov. sp. nov., a strictly anaerobic bacterium utilizing dichloromethane as source of carbon and energy. Archives of Microbiology, 166(2), 101-108. https://doi.org/10.1007/s002030050362

McCulloch, A. (2017). Dichloromethane in the environment: A note prepared for the European Chlorinated Solvents Association (ECSA) and the Halogenated Solvents Industry Alliance (HSIA). http://www.chlorinated-solvents.eu/images/Documents/Newsroom/Dichloromethane paper.pdf

Mulder, I., Huber, S. G., Krause, T., Zetzsch, C., Kotte, K., Dultz, S., \& Schöler, H. F. (2013). A new purge and trap headspace technique to analyze low volatile compounds from fluid inclusions of rocks and minerals. Chemical Geology, 358, 148-155. https://doi.org/10.1016/J.CHEMGEO.2013.09.003

Muller, E. E. L., Bringel, F., \& Vuilleumier, S. (2011). Dichloromethane-degrading bacteria in the genomic age. Research in Microbiology, 162(9), 869-876. https://doi.org/10.1016/J.RESMIC.2011.01.008

Muyzer, G., De Waal, E. C., \& Uitterlinden, A. G. (1993). Profiling of complex microbial populations by denaturing gradient gel electrophoresis analysis of polymerase chain reaction-amplified genes coding for 16S rRNA. Applied and Environmental Microbiology, 59(3), 695-700. https://doi.org/10.1128/aem.59.3.695-700.1993

Ooki, A., \& Yokouchi, Y. (2011). Dichloromethane in the Indian Ocean: Evidence for in-situ production in seawater. Marine Chemistry, 124(1-4), 119-124. https://doi.org/10.1016/J.MARCHEM.2011.01.001

Pagès, H., Aboyou, P., Gentleman, R., \& DebRoy, S. (2019). Biostrings: Efficient manipulation of biological strings ( $R$ package version 2.54.0).

Petkau, A., Stuart-Edwards, M., Stothard, P., \& Van Domselaar, G. (2010). Interactive microbial genome visualization with GView. Bioinformatics, 26(24), 3125-3126. https://doi.org/10.1093/bioinformatics/btq588

Price, M. N., Dehal, P. S., \& Arkin, A. P. (2010). FastTree 2 - Approximately maximum-likelihood trees for large alignments. PLOS ONE, 5(3), e9490. https://doi.org/10.1371/journal.pone.0009490

Price, M. N., Zane, G. M., Kuehl, J. V, Melnyk, R. A., Wall, J. D., Deutschbauer, A. M., \& Arkin, A. P. (2018). Filling gaps in bacterial amino acid biosynthesis pathways with high-throughput genetics. PLOS Genetics, 14(1), e1007147. https://doi.org/10.1371/journal.pgen.1007147

Ritalahti, K. M., Amos, B. K., Sung, Y., Wu, Q., Koenigsberg, S. S., \& Löffler, F. E. (2006). Quantitative PCR targeting 16S rRNA and reductive dehalogenase genes simultaneously monitors multiple Dehalococcoides strains. Applied and Environmental Microbiology, 72(4), 2765-2774. https://doi.org/10.1128/AEM.72.4.2765-2774.2006

Roosild, T. P., Castronovo, S., Healy, J., Miller, S., Pliotas, C., Rasmussen, T., Bartlett, W., Conway, S. 
804

805

806

807

808

809

810

811

812

813

814

815

816

817

818

819

820

821

822

823

824

825

826

827

828

829

830

831

832

833

834

835

836

837

838

839

840

841

842

843

844

845

846

847

848

849

850

851

852

853

854

J., \& Booth, I. R. (2010). Mechanism of ligand-gated potassium efflux in bacterial pathogens.

Proceedings of the National Academy of Sciences of the United States of America, 107(46), 1978419789. https://doi.org/10.1073/pnas.1012716107

Seeman, T. (2018). tseemann/barrnap: Bacterial ribosomal RNA predictor (0.9-2). https://github.com/tseemann/barrnap

Sousa, D. Z., Visser, M., van Gelder, A. H., Boeren, S., Pieterse, M. M., Pinkse, M. W. H., Verhaert, P. D. E. M., Vogt, C., Franke, S., Kümmel, S., \& Stams, A. J. M. (2018). The deep-subsurface sulfate reducer Desulfotomaculum kuznetsovii employs two methanol-degrading pathways. Nature Communications, 9(1), 239. https://doi.org/10.1038/s41467-017-02518-9

Stramma, L., Johnson, G. C., Sprintall, J., \& Mohrholz, V. (2008). Expanding oxygen-minimum zones in the tropical oceans. Science, 320(5876), 655-658. https://doi.org/10.1126/science.1153847

Suttner, B. J., Johnston, E. R., Orellana, L. H., Rodriguez-R, L. M., Hatt, J. K., Carychao, D., Carter, M. Q., \& Cooley, M. B. (2020). Potential and limitations of metagenomics as a public health risk assessment tool in a study of natural creek sediments influenced by agricultural and livestock runoff. Appl. Environ. Microbiol., 86(6), e02525-19. https://doi.org/10.1128/AEM.02525-19

Svensen, H., Planke, S., Polozov, A. G., Schmidbauer, N., Corfu, F., Podladchikov, Y. Y., \& Jamtveit, B. (2009). Siberian gas venting and the end-Permian environmental crisis. Earth and Planetary Science Letters, 277(3-4), 490-500. https://doi.org/10.1016/J.EPSL.2008.11.015

Tatusov, R. L., Galperin, M. Y., Natale, D. A., \& Koonin, E. V. (2000). The COG database: a tool for genome-scale analysis of protein functions and evolution. Nucleic Acids Research, 28(1), 33-36. https://www.ncbi.nlm.nih.gov/pmc/articles/PMC102395/

Thamdrup, B., Steinsdóttir, H. G. R., Bertagnolli, A. D., Padilla, C. C., Patin, N. V., Garcia-Robledo, E., Bristow, L. A., \& Stewart, F. J. (2019). Anaerobic methane oxidation is an important sink for methane in the ocean's largest oxygen minimum zone. Limnology and Oceanography, 64(6), 25692585. https://doi.org/10.1002/Ino.11235

Trudinger, C. M., Etheridge, D. M., Sturrock, G. A., Fraser, P. J., Krummel, P. B., McCulloch, A., \& Etheridge, M. (2004). Atmospheric histories of halocarbons from analysis of Antarctic firn air: Methyl bromide, methyl chloride, chloroform, and dichloromethane. J. Geophys. Res, 109, 22310. https://doi.org/10.1029/2004JD004932

Vannelli, T., Messmer, M., Studer, A., Vuilleumier, S., \& Leisinger, T. (1999). A corrinoid-dependent catabolic pathway for growth of a Methylobacterium strain with chloromethane. Proceedings of the National Academy of Sciences of the United States of America, 96(8), 4615-4620. https://doi.org/10.1073/pnas.96.8.4615

Vit, O., \& Petrak, J. (2017). Integral membrane proteins in proteomics. How to break open the black box? Journal of Proteomics, 153, 8-20. https://doi.org/10.1016/J.JPROT.2016.08.006

Wever, R., \& Barnett, P. (2017). Vanadium chloroperoxidases: The missing link in the formation of chlorinated compounds and chloroform in the terrestrial environment? Chemistry - An Asian Journal, 12(16), 1997-2007. https://doi.org/10.1002/asia.201700420

Wiechmann, A., Ciurus, S., Oswald, F., Seiler, V. N., \& Müller, V. (2020). It does not always take two to tango: "Syntrophy" via hydrogen cycling in one bacterial cell. ISME Journal, 14(6), 1561-1570. https://doi.org/10.1038/s41396-020-0627-1

Wong, Y. K., Holland, S. I., Ertan, H., Manefield, M., \& Lee, M. (2016). Isolation and characterization of Dehalobacter $s p$. strain UNSWDHB capable of chloroform and chlorinated ethane respiration. Environmental Microbiology, 18(9), 3092-3105. https://doi.org/10.1111/1462-2920.13287

Wright, J., Kirchner, V., Bernard, W., Ulrich, N., McLimans, C., Campa, M. F., Hazen, T., Macbeth, T., Marabello, D., McDermott, J., Mackelprang, R., Roth, K., \& Lamendella, R. (2017). Bacterial community dynamics in dichloromethane-contaminated groundwater undergoing natural attenuation. Frontiers in Microbiology, 8, 2300. https://doi.org/10.3389/fmicb.2017.02300

Wu, S., Zhu, Z., Fu, L., Niu, B., \& Li, W. (2011). WebMGA: a customizable web server for fast metagenomic sequence analysis. BMC Genomics, 12(1), 444. https://doi.org/10.1186/1471-2164$12-444$

Wuosmaa, A. M., \& Hager, L. P. (1990). Methyl chloride transferase: A carbocation route for biosynthesis of halometabolites. Science, 249(4965), 160-162. https://www-jstororg.proxy.lib.utk.edu/stable/pdf/2874545.pdf?refreqid=excelsior\%3Ae86ae7d382fcc008630b1329bb b843ee

Yang, S., Giannone, R. J., Dice, L., Yang, Z. K., Engle, N. L., Tschaplinski, T. J., Hettich, R. L., \& Brown, 
bioRxiv preprint doi: https://doi.org/10.1101/2021.08.30.458270; this version posted August 31, 2021. The copyright holder for this preprint (which was not certified by peer review) is the author/funder. All rights reserved. No reuse allowed without permission. 